\title{
Davids, Goliaths, and Business Cycles
}

\author{
Jefferson Duarte and Nishad Kapadia*
}

April 2013

\begin{abstract}
We show that a simple, intuitive variable, GVD (Goliath versus David) reflects timevariation in discount rates related to changes in aggregate business conditions. $G V D$ is the annual change in the weight of the largest 250 firms in the aggregate stock market, and is motivated by research that shows that small firms are more severely impacted than large firms by economic shocks due to differences in access to external finance. We find that $G V D$ is the best single predictor of market returns out-of-sample among traditional predictors, predicting quarterly market returns with an out-of-sample $R^{2}$ of $6.3 \%$ in the 1976-2011 evaluation period. Consistent with its motivation, GVD forecasts lower future GDP and aggregate investment growth. GVD also forecasts returns on treasury bonds and the 25 size and book-to-market sorted portfolios (and consequently $H M L$ as well as $S M B$ ), with assets we ex-ante expect to be more sensitive to discount rate variation displaying greater sensitivity to $G V D$. We show that $G V D$ is the only variable among traditional predictors that forecasts stock returns, bond returns, and macroeconomic variables. We also show that $G V D$ 's predictive ability is robust, and not due to information contained in traditional variables, such as $S M B$ and net payout.
\end{abstract}

${ }^{*}$ The authors are with Jesse H. Jones Graduate School of Business at Rice University. We thank Caio de Almeida, Kerry Back, Miguel Ferreira, Wayne Ferson, Michael Lemmon, Brad Paye, Jeffrey Pontiff, Allan Timmermann, Pietro Veronesi, James Weston, our colleagues at Rice University, and participants at the $12^{\text {th }}$ Brazilian Finance Meeting for helpful comments. Address: 6100 Main St. MS 531, Houston, TX 77005. E-mail addresses: jefferson.duarte@rice.edu and nishad.kapadia@rice.edu. All remaining errors are our own. 
An intuitive result underlying many rational asset pricing models is that discount rates vary with business cycles (Campbell and Cochrane (1999)). Discount rates are high during economic downturns, when "few people have the guts or the wallet to buy risky stocks or risky long-term bonds" (Cochrane (1999)). However, simple economically-motivated variables related to aggregate business conditions, such as the term spread and default spread, have not proved to be reliable predictors of market returns. In an influential paper, Goyal and Welch (2008) find that the predictive ability of traditional forecasting variables has greatly diminished after the oil shocks of the 1970s and, as a result, none of these variables predict market returns out-of-sample. They emphasize that the lack of predictive power over the last three decades raises questions about whether these variables will be able to predict market returns in the future. In addition, Fama and French (1989) argue that it is appealing from the perspective of rational time-variation in discount rates if a predictor of market returns also forecasts bond returns and varies with aggregate business conditions. However, as we show below, none of the traditional forecasting variables succeed in jointly forecasting stock returns, bond returns and macroeconomic variables even in-sample over our sample period. ${ }^{1}$ Thus, a question remains: given the intuition that discount rates vary with business cycles, can economic theory guide us in constructing a variable that reflects discount rate variation, and therefore predicts stock returns, bond returns and aggregate business conditions, both in-sample and out-of-sample?

One way to build such a variable is to utilize the cross-section of stocks: changes in the valuation of firms that we expect to be most impacted by economic downturns relative to those that we expect to be least impacted should be correlated with discount rate variation. We know from the business cycle literature that the largest firms in the economy are not as severely affected by aggregate economic shocks as the rest of the firms in the stock market. Theoretical research (e.g. Bernanke and Gertler (1989)) implies that following aggregate economic shocks, small firms find it harder to access external finance, causing lower aggregate investment and thereby amplifying the original shock. Empirical research finds support for the differential effect of aggregate economic shocks on

\footnotetext{
${ }^{1}$ The variables we consider are: default spread, term spread, dividend-price ratio, net payout, smoothed price-toearnings ratio, book-to-market ratio, consumption-wealth ratio (CAY), and investment-to-capital ratio. We are not aware of recent research that examines forecasting for both stocks and bonds, with the exception of Cochrane and Piazzesi (2005), who show that their bond return forecasting variable also predicts stock returns.
} 
small versus large firms. ${ }^{2}$ In particular, two empirical papers provide evidence that discount rates for small firms increase more than those for large firms during economic downturns. First, Perez-Quiros and Timmermann (2000) show that small firms exhibit greater increases in expected returns during recessionary states. Second, Covas and Den Haan (2011) find that small firms also have much more cyclical equity issuance than do large firms, suggesting that the cost of equity of small firms has greater correlation with aggregate economic conditions than that of large firms. Thus, increases in the market value of large firms relative to small firms should signify a period of economic stress in which market discount rates are high.

We propose a simple variable, Goliath Versus David (or $G V D$ ), that embodies the insights of this literature. $G V D$ is the change in weight of the largest 250 stocks in the aggregate market portfolio over a 12-month period. We show that $G V D$ can be decomposed into two components: the difference between the return on existing capital of the largest 250 firms and the market $\left(G V D_{O L D}\right)$, and the difference in net new equity issuances between the largest 250 firms and the market $\left(G V D_{N E W}\right){ }^{3}$ $G V D$ therefore combines the two consequences of differential discount rates shocks for small and large firms in economic downturns described above, into a single, economically-intuitive variable. Thus, GVD should increase in economic downturns when discount rates are high and hence, should predict high aggregate market returns in such times. In addition, the Bernanke and Gertler (1989) model also implies that the increase in the cost of external finance causes lower aggregate investment, and hence increases in GVD should predict declines in GDP growth and aggregate investment. Finally, if $G V D$ reflects changes in discount rates, $G V D$ should also predict treasury bond returns.

We begin by confirming the hypothesis that $G V D$ varies with contemporaneous business conditions. We find that $G V D$ rises during recessions and has a rank correlation of - $24 \%$ with contemporaneous $G D P$ growth. $G V D$ also has local maxima during periods of financial market stress, such as the crash of October 1987 and the bailout of Long Term Capital Management (LTCM) in September

\footnotetext{
${ }^{2}$ For example, Gertler and Gilchrist (1994) find that small firms have lower investments and sales growth than large firms following macroeconomic shocks. Bernanke, Gertler, and Gilchrist (1996) term the amplification of macroeconomic shocks through financial markets as the "financial accelerator" mechanism for the transmission of aggregate shocks. Other theoretical work that has similar implications includes Kiyotaki and Moore (1997). See Bernanke, Gertler, and Gilchrist (1999) for a survey of both empirical and theoretical research on this topic.

${ }^{3}$ Note that this decomposition also highlights how $G V D$ is distinct from $S M B$, the Fama-French factor that measures the difference in return between small and large stocks, since $S M B$ is only related to $G V D_{O L D}$ and not to $G V D_{N E W}$.
} 
1998, where there is a possibility of a severe aggregate shock, which may not be eventually realized. It is likely that discount rates increase during such events. ${ }^{4}$ If the feared adverse outcome is not realized, it will not be seen in macroeconomic data, suggesting an advantage of using variables that are based on market expectations, such as $G V D$, to measure discount rate variation relative to using macroeconomic variables. Another advantage of using financial market-based variables is that markets are forward-looking and anticipate (Schwert (1990)) or even cause (Bernanke and Gertler (1989)) macroeconomic outcomes; hence $G V D$ may lead macroeconomic variables.

Our next step is to test whether $G V D$ forecasts market returns, business cycle related variables (GDP growth and investment growth), and treasury bond returns, both in-sample and out-ofsample. GVD performs remarkably well in these tests, both in absolute terms, as well as relative to traditionally used forecasting variables. In-sample, $G V D$ significantly predicts quarterly nonoverlapping market returns $\left(R^{2}=3.3 \%\right)$, monthly five-year treasury bond returns $\left(R^{2}=0.7 \%\right)$, quarterly $G D P$ growth $\left(R^{2}=4.1 \%\right)$, and quarterly aggregate investment growth $\left(R^{2}=6.9 \%\right)$. None of the benchmark variables predict more than two of these four series, with the consumption-wealth ratio $(C A Y)$ of Lettau and Lydvigson (2001) being the only benchmark variable to significantly predict both bond and stock returns. Out-of-sample, for the post oil-shock evaluation period (19752011), GVD significantly predicts quarterly non-overlapping market returns $\left(R^{2}=6.4 \%\right)$, quarterly aggregate investment growth $\left(R^{2}=9.0 \%\right)$, and monthly bond returns $\left(R^{2}=0.4 \%\right)$. Note that $G V D$ 's forecasting ability actually improves in the post oil-shock sample, thereby addressing the Goyal and Welch (2008) critique that traditional variables do not forecast market returns over the last three decades. In out-of-sample tests, none of the benchmark variables (including $C A Y$ ) have positive $R^{2} \mathrm{~s}$ in predicting market returns, only the term spread significantly predicts bond returns, and only the default spread significantly predicts GDP growth and aggregate investment growth. These results show that $G V D$ reflects variation in discount rates related to aggregate business conditions.

Next, we deepen our understanding of $G V D$ 's predictive ability by using four sets of tests that examine its robustness and consistency with its theoretical motivation. First, we examine GVD's

\footnotetext{
${ }^{4}$ Caballero and Krishnamurthy (2008) discuss events such as these in greater detail and present a model in which such periods of greater "Knightian" uncertainty result in a flight to quality.
} 
ability to forecast market returns in greater detail since prior research documents several potential statistical pitfalls in predicting market returns. We find that $G V D$ 's forecasting ability is robust to standard critiques of market return predictability, and survives controlling for other predictors. ${ }^{5}$

Second, we examine whether $G V D$ 's forecasting ability arises predominantly from one of its two components, $G V D_{O L D}$ or $G V D_{N E W}$, or whether both are important. As discussed above, prior research suggests that changes in discount rates in economic downturns result in changes in each component. We find that each component by itself is a significant, but much weaker, predictor of market returns. Using both components to forecast market returns not only improves overall predictive ability, but also increases the significance of each component. This improvement occurs because both components have coefficients of similar magnitudes in predicting market returns and have low-in fact negative-correlations with each other. Thus, both components provide distinct signals of discount rate variation. ${ }^{6}$

Third, we examine $G V D$ 's business cycle properties and test two implications of the Bernanke and Gertler (1989) model: first, GVD should forecast aggregate investment even after controlling for current economic conditions and second, GVD's forecasting ability should be stronger during economic downturns when credit constraints bind, and $G V D$ is therefore more informative of aggregate business conditions. We find evidence consistent with both implications. In particular, increases in $G V D$ forecast declines in real private fixed investment growth even after controlling for lagged investment growth and lagged market returns. We also find that GVD's coefficient in forecasting market returns when $G D P$ growth is below its median is five times as large as compared

\footnotetext{
${ }^{5}$ In particular, we focus on predicting quarterly non-overlapping returns to avoid biases in standard errors of overlapping returns (Ang and Bekaert (2007)); GVD is less likely to be data-mined since it is less persistent than standard predictors (Ferson, Sarkissian, and Simin (2003)); GVD's predictive ability is robust to the Stambaugh (1999) bias, changing its definition to the largest 500 instead of 250 stocks, excluding influential periods such as the oil shocks and the internet period, and alternative start dates for the out-of-sample evaluation period (Hansen and Timmermann (2012)). GVD's predictive ability is unlikely to arise due to lead-lag relations between small and large firm returns since $G V D$ also predicts market returns after skipping a quarter between computing $G V D$ and measuring market returns, Similarly $G V D$ 's predictive ability is unlikely to arise from persistence in market returns, since $G V D$ continues to predict market returns after controlling for lagged market returns.

${ }^{6}$ We find that $S M B$ does not significantly predict market returns by itself; however when we control for $G V D_{N E W}$ in predicting market returns, the coefficient on $S M B$ becomes significant. This perhaps explains why prior research on $S M B$ has not uncovered its ability to predict market returns, even though there is a long literature that suggests it should be correlated with discount rate variation (e.g. Perez-Quiros and Timmermann (2000) and Fama and French (1996)).
} 
to when GDP growth is above its median. ${ }^{7}$ These results are consistent with the literature that argues that financial markets-in particular, access to external finance-has real effects (Bernanke and Gertler (1989)).

Fourth, following Fama and French (1989), we test whether $G V D$ forecasts other asset returns and whether assets we expect ex-ante to be more sensitive to discount rate variation exhibit greater sensitivity to $G V D$. We find that $G V D$ significantly predicts excess returns of treasury bonds of maturities from one to ten years. The coefficients on GVD in these regressions increase monotonically with the maturity of the bonds, consistent with longer duration bonds having greater sensitivity to discount rates. We also examine an analogous regression in the cross-section of stock returns. Prior research finds that growth stocks have a higher duration of cash flows than do value stocks and are therefore more sensitive to discount rates (Campbell and Vuolteenaho (2004) and Lettau and Wachter (2007)). Thus, we expect that growth stocks are more sensitive than value stocks to variation in discount rates as measured by $G V D$. Moreover, the Bernanke and Gertler (1989) model predicts that firms with relatively low collateral will be most impacted by an economic shock. Small, growth firms whose valuation is driven by growth opportunities rather than assets in place are likely to have low values of collateral and should be more sensitive to changes in GVD. We find that this is indeed the case. In regressions predicting the returns of the Fama-French 25 size and book-to-market sorted portfolios using $G V D$, we find that $G V D$ coefficients increase as we move from value to growth within each size quintile and also increase as we move from large to small within each book-to-market quintile. Consequently, GVD also significantly predicts the Fama-French factors, $H M L$ and $S M B$.

Our paper is related to research that examines market return predictability and especially to recent research that responds to the Goyal and Welch (2008) critique. In particular, our results complement those in Rapach, Strauss, and Zhou (2010), Campbell and Thompson (2008), Ferreira and Santa-Clara (2011), and Kelly and Pruitt (2012), all of whom develop alternate estimation techniques for expected returns that succeed in predicting market returns out-of-sample. The out-of-

\footnotetext{
${ }^{7}$ We thank Allan Timmermann for suggesting this test. These results are consistent with Henkel, Martin, and Nardari (2011), who find that the forecasting ability of common market return predictors is higher during recessions.
} 
sample predictability for market returns that we document is comparable to these papers. ${ }^{8}$ Relative to these papers, our contribution is to develop a new economically-motivated variable that also predicts bond returns and macroeconomic variables.

We also contribute to the literature that relates business cycles with financial constraints. For example, the Bernanke and Gertler (1990) model implies that during bad times, when net worth is low, financing constraints cause lower investments. Bernanke, Gertler, and Gilchrist (1996) point out the empirical challenge of testing this theory: lead-lag relationships between credit availability and economic output can result from changes in expectations about output rather than from a causal link between credit availability and economic activity. Consequently, empirical research examines this theory through its cross-sectional implications and uses firm size as a proxy for financial constraints. We contribute to this literature because we show that $G V D$, a measure of the relative valuation of small and large firms, forecasts asset returns and real economic activity.

Our results are also consistent with another, closely-related hypothesis. Subrahmanyam and Titman (2012) develop a model in which positive shocks to stock market participation lead to lower expected returns and larger investment from firms that have no assets other than options to invest. This investment by entrepreneurial firms leads to a decrease in the expected cash flows and an increase in the expected rate of churn for large, established companies in a process of creative destruction. Since $G V D$ reflects changes in the market expectations of the rate of churn of large and established firms, our results are consistent with Subrahmanyam and Titman (2012). ${ }^{9}$ Since models based on both credit constraints and creative destruction predict that decreases in the cost of capital cause reduced investment by small firms with growth options, they are difficult to distinguish empirically. We do not attempt to do so; rather we focus on testing whether $G V D$ reflects discount rate variation and aggregate business conditions.

The remainder of the paper proceeds as follows: Section 1 defines GVD. Section 2 describes the data used throughout the paper along with general summary statistics. Section 3 provides

\footnotetext{
${ }^{8}$ For example, Kelly and Pruitt (2012) report that their three-pass regression filter beats other estimators with an out-of-sample $R^{2}$ of between $0.44 \%$ and $0.76 \%$ for monthly returns (Table 1 of their paper). For exactly the same evaluation period (1980-2009), GVD's out-of-sample $R^{2}$ is $0.99 \%$.

${ }^{9}$ In fact, GVD is similar to measures of creative destruction in Fogel, Morck, and Yeung (2008) and Liang, McLean, and Zhao (2011), who use measures of churn of the largest firms based on revenues or employees, rather than market capitalization.
} 
an overview of $G V D$ 's ability to forecast aggregate market returns, bond returns, $G D P$ as well as aggregate investment growth, and benchmarks its forecasting ability against that of traditional forecasting variables. Section 4 examines forecasting regressions for the market in greater detail. Section 5 addresses the source of $G V D$ 's forecasting ability, by examining its components, businesscycle properties, and its ability to forecast bond returns and returns on portfolios formed from sorts on size and book-to-market. Section 6 concludes.

\section{$1 G V D$ (Goliath versus David)}

We define $G V D$ as:

$$
G V D_{t, \Delta t}^{m}=\ln \left(\frac{P_{m, t}}{P_{M, t}}\right)-\ln \left(\frac{P_{m, t-\Delta t}}{P_{M, t-\Delta t}}\right)
$$

where $P_{m, t}$ is the sum of the market capitalization at time $t$ of the $m$ firms with the largest market capitalization at time $t-\Delta t, P_{m, t-\Delta t}$ is the sum of the market capitalization at time $t-\Delta t$ of the $m$ firms with the largest market capitalization at time $t-\Delta t, P_{M, t}$ is the sum of the market capitalization of all firms in the market at time $t$, and $P_{M, t-\Delta t}$ is the sum of the market capitalization of all firms in the market at time $t-\Delta t$. That is, $G V D_{t, \Delta t}^{m}$ is the change in the log of the weight of the $m$ largest firms at time $t-\Delta t$ in the market portfolio.

Note that $G V D$ is not just the difference between the return of the portfolio of the $m$ largest firms and the market portfolio. In fact, we show in the appendix that:

$$
G V D_{t, \Delta t}^{m}=\left(E x R_{t, \Delta t}^{m}-E x R_{t, \Delta t}^{M}\right)+\left(G_{t, \Delta t}^{m}-G_{t, \Delta t}^{M}\right)
$$

where $\operatorname{Ex} R_{t, \Delta t}^{m}$ is the ex-dividend return (return related to price appreciation only) between $t$ and $t-\Delta t$ of the portfolio of the $m$ largest stocks at time $t-\Delta t$, and $G_{t, \Delta t}^{m}$ is the rate of growth of this portfolio due to new stock issuances. Similarly, $E x R_{t, \Delta t}^{M}$ and $G_{t, \Delta t}^{M}$ are the ex-dividend return and the growth rate of the market portfolio. The exact expression for the rate of growth and ex-dividend

return are in the Appendix. We refer to $\left(E x R_{t, \Delta t}^{m}-E x R_{t, \Delta t}^{M}\right)$ and to $\left(G_{t, \Delta t}^{m}-G_{t, \Delta t}^{M}\right)$ as the returns component $\left(G V D_{O L D}\right)$ and the capital-raising component $\left(G V D_{N E W}\right)$ of $G V D$ respectively. 


\section{Data and summary statistics}

In this section, we describe in detail how we construct $G V D$ (Section 2.1), the variables we forecast using $G V D$ (Section 2.2), and the variables we use to benchmark $G V D$ 's forecasting performance (Section 2.3).

\subsection{Computing $G V D$}

We set the period $\Delta t$ equal to one year in our implementation of $G V D_{t, \Delta t}^{m}$. A shorter period for $\Delta t$ may introduce noise to $G V D$ unrelated to business cycle information, while a longer period may eliminate variation related to business cycles. In addition, most of the empirical analysis in this paper is done with $G V D_{t, \Delta t}^{250}$ (we set $m$ equal to 250). We use 250 firms as the cut-off in order to have a relatively large number of companies both above and below the cut-off for our entire sample period (1926:4 to 2011:4). We also show below that $G V D$ 's forecasting ability is robust to setting $m$ equal to 500 firms. In fact, $G V D_{t, 1}^{500}$ 's forecasting ability is better than that of $G V D_{t, 1}^{250}$ in some of the analysis that we perform. However, we do not use $G V D_{t, 1}^{500}$ as our main $G V D$ variable because there are only about 500 firms in the first few years of our sample period. We calculate $G V D_{t, 1}$ at the end of every month using monthly data from the Center for Research in Security Prices (CRSP). We only use ordinary shares (CRSP codes 10 and 11) to build our measure.

\subsection{Dependent variables}

We forecast several variables using $G V D$ in this paper. These include the equity risk premium, real GDP and real private fixed investment growth, returns on US bonds, returns on the Fama-French factors, $H M L$ and $S M B$, and returns on the 25 size and book-to-market portfolios. All returns are arithmetic.

- The market risk premium $(M K T R F)$ : $M K T R F$ is the return of the value-weighted CRSP index over the risk-free rate. We primarily focus on forecasting quarterly non-overlapping market excess returns, where returns are measured in excess of the three-month risk-free rate from the CRSP risk-free rate file. For monthly excess returns we use returns in excess of the 
monthly risk-free rate and for annual excess returns we compound the three-month risk-free rate to the annual frequency.

- Real $G D P$ Growth $(G D P G): G D P G$ is the change in logs of the quarterly real seasonally adjusted $G D P$ series from FRED, the online database of the St. Louis Federal Reserve.

- Real Private Fixed Investment Growth $(P F I G)$ : Similarly, PFIG is the change in logs of quarterly real (quantity series) seasonally adjusted private fixed investment from the Bureau of Economic Analysis.

- $H M L, S M B$ and 25 size and book-to-market sorted portfolios: Returns on $H M L, S M B$ and the 25 size and book-to-market sorted portfolios are from Wharton Research Data Services (WRDS). These are arithmetic quarterly returns for $H M L$ and $S M B$ and arithmetic quarterly returns in excess of the 3 month risk-free rate for the 25 size and book-to-market sorted portfolios.

- Bond returns: Bond returns are monthly returns of constant maturity CRSP indices. The maturities we consider are 90 days, 1 year, 2 year, 5 year, and 10 year. We subtract out the 30 day risk-free rate from each bond return to get bond excess returns. We focus our analysis on monthly returns of these indices, since the indices change every month to remain constant maturity.

\section{$2.3 \quad$ Benchmarks}

We compare the forecasting performance of $G V D$ with the performance of a series of predictors proposed in the literature. We focus our choice of benchmarks on predictors that are commonly used and on those that perform well in-sample according to Goyal and Welch (2008). We use three broad sets of predictors - interest rate variables, valuation ratios, and macroeconomic variables:

- Interest-rate variables: These are the default spread (DS) and the term spread (TS). DS is the difference between BAA and AAA bond yields and TS is the difference in the yield of the 10-year Treasury note and the 3 month bill. Although Goyal and Welch (2008) find no 
evidence that these variables forecast aggregate stock returns even in-sample, we include them because they are commonly used in the literature (e.g. Fama and French (1989)) and may predict the other independent variables that we consider.

- Valuation ratios: The valuation ratios we use are the dividend-price ratio (DP) examined in Fama and French (1988) and Campbell and Shiller (1988a) and in many other papers, the cyclically-adjusted price-earnings ratio (CAPE) from Campbell and Shiller (1988b), the bookto-market ratio of the DJIA (BM) from Pontiff and Schall (1998), and the net-payment yield of all stocks using the CRSP data (CRSPNPY) from Boudoukh, Michaely, Richardson, and Roberts (2007).

- Macroeconomic variables: The macroeconomic variables we use are the consumption-wealth ratio $(C A Y)$ from Lettau and Lydvigson (2001), and the investment-to-capital ratio (IK) from Cochrane (1991). Since Goyal and Welch (2008) find that these variables predict stock returns in-sample, we include all of them as benchmarks for evaluating $G V D$ 's forecasting power.

The sources for each of these variables are described in Table 1.

\subsection{Summary Statistics}

Table 1, Panel A displays summary statistics for each of the predictor variables used in this paper. The mean of $G V D_{t, 1}^{250}$ is $-2.4 \%$. The negative sign of this mean is consistent with the increase in the importance of smaller firms in the stock market during our sample period. Note that since we measure $G V D$ as a difference, we are robust to non-stationarity issues related to the increase in the share of small firms in the sample over time. The autocorrelation of $G V D_{t, 1}^{250}$ when sampled at the quarterly frequency is 0.702 , and 0.116 when sampled annually. In addition, Dickey-Fuller tests reject the unit-root null at the usual significance levels. These autocorrelations are smaller than the autocorrelation of the benchmark predictors in Panel A. At the quarterly frequency, autocorrelations of all benchmark variables are above 0.9 , while at the annual frequency, autocorrelations are above 0.7. This is important because prior research finds that the high persistence of predictor variables used in forecasting aggregate market returns can create statistical problems (e.g. Stambaugh (1999) 
and Ferson, Sarkissian, and Simin (2003)). Given GVD's relatively low persistence, we do not expect that the issues described in Stambaugh (1999) and Ferson, Sarkissian, and Simin (2003) are as serious for $G V D$ as they are for some commonly used forecasting variables such as dividendyield. This conjecture is confirmed in Section 4.1. The low persistence of $G V D$ is also consistent with recent evidence in Kelly and Pruitt (2012) who find that their predictor is less persistent than traditional variables. Also note that the summary statistics of $G V D_{t, 1}^{500}$ are similar to those of $G V D_{t, 1}^{250}$.

Panel B of Table 1 displays the correlations between $G V D_{t, 1}^{250}, G V D_{t, 1}^{500}, G V D_{O L D}, G V D_{N E W}$, annual returns on $S M B$, and the set of benchmark variables. This panel reveals that the correlation of $G V D_{t, 1}^{500}$ with $G V D_{t, 1}^{250}$ is high at 0.92 . The correlation between $G V D_{t, 1}^{250}$ and $S M B$ is -0.41 . This relatively high correlation is not surprising because of the conceptual connection between the returns component of GVD and the size factor (see Equation 2). This high correlation arises from the return differential component of $G V D, G V D_{O L D}$. $G V D_{O L D}$ has a correlation of -0.79 with $S M B$, while the capital raising component, $G V D_{N E W}$, has a correlation with $S M B$ of the opposite sign of 0.39. We show in Section 5.1 that both components are important in forecasting market returns and each component by itself is a much weaker predictor of market returns than $G V D$. Also note that $G V D_{N E W}$ and $C R S P N P Y$ are related but distinct. The difference between the two is that $C R S P N P Y$ includes dividends while $G V D_{N E W}$ does not, and $C R S P N P Y$ subtracts the total net equity issuance for the market from aggregate dividends, while $G V D_{N E W}$ is the difference in net equity issuance between the largest 250 firms and the market. Covas and Den Haan (2011) show that the latter difference is important for the cyclical properties of these variables. They find that aggregate issuances for the largest firms are slightly countercyclical, while small firm issuances are procyclical, with the degree of cyclicality increasing as size decreases. They also report that issuances by the largest $1 \%$ of firms are so large that they have a significant impact on the aggregate market issuances. Therefore even though equity issuances are procyclical for an overwhelming majority of firms, they are not procyclical in aggregate. We see that the correlation between $G V D_{N E W}$ and $C R S P N P Y$ is 0.34 . Relative to other correlations, it is by no means extraordinary; for example, $C R S P N P Y$ has higher absolute correlations with the investment-to-capital ratio $I K$. 


\section{$3 \quad G V D$ 's forecasting ability}

In this section we document $G V D$ 's forecasting ability and benchmark it to that of traditional predictive variables used by prior research. We first describe time-series variation in $G V D$ and its relation with contemporaneous aggregate business conditions in Section 3.1. We then examine the ability of $G V D$ and our benchmark variables to forecast stock market excess returns, bond market excess returns, GDP growth and private fixed investment growth. Section 3.2 performs an in-sample analysis, while Section 3.3 performs an out-of-sample analysis. These sections examine univariate forecasting regressions with no controls and allows us to compare the forecasting ability of $G V D$ with that of the benchmark variables. Sections 4 and 5 investigate $G V D$ 's forecasting ability for each of these series in greater detail, add additional controls relevant to each series, and conduct robustness tests.

\section{1 $G V D$ and contemporaneous business conditions}

Figure 1 plots the quarterly time series of $G V D_{t, 1}^{250}$ from 1926:4 to 2011:4 along with NBER recessions. This plot clearly shows that $G V D_{t, 1}^{250}$ rises during recessions and falls during expansions; that is, the weight of large firms in the stock market portfolio increases in recessions and decreases in expansions. The rank correlation of $G V D$ with quarterly GDP growth is $-24 \%$. This suggests that in terms of valuations, giant "Goliaths" handle recessions better than small "Davids", but that "Davids" outperform "Goliaths" during expansions.

The figure also includes text-boxes that correspond to local maxima or minima of $G V D$ that are not in recessions. The text-boxes contain the date of the maxima or minima and proximate events that had an impact on financial markets. Note that the event may be spread over several months or occur in a different month, proximate to the local maxima or minima. Working chronologically

backwards, the first text-box corresponds to the peak in GVD in April 2003. The United States invaded Iraq on March 19, 2003. The next text-box corresponds to a peak in September 1998. LTCM collapsed in September 1998, and was rescued in a bailout by a group of financial institutions under the supervision of the Federal Reserve on September 23, 1998. The next peak is in April 1997. 
In February 1997, the first of many Thai property developers announced a default on a dollar denominated loan, leading to speculative attacks on the Thai baht, and an eventual lifting of its peg to the US dollar in July 1997. These events culminated in the "Asian crisis" that impacted several Asian economies including Indonesia, Malaysia, Singapore and South Korea. The next box corresponds to a peak in May 1995; GVD rises from a trough of $-9.6 \%$ in September 1993 to $0 \%$ in January 1994, remaining at that level till its peak of $0.2 \%$ in May 1995. This period corresponds to the "peso crisis" in Mexico. Mexico was forced to allow the peso to float against the US dollar on December 20, 1994, resulting in a severe devaluation of the peso and a rise in interest rates on Mexican debt over the next few months. Other notable peaks occur in September 1992, corresponding to "Black Wednesday" when the United Kingdom withdrew from the Exchange Rate Mechanism (ERM) due to speculative attacks on the pound, "Black Monday" in October 1987, and August 1939, on the eve of World War II (Germany invaded Poland on September 1, 1939).

Caballero and Krishnamurthy (2008) present a model in which there is greater "Knightian" uncertainty in periods of market stress, such as the collapse LTCM and the stock market crash in October 1987, resulting in a flight to quality. As described above, GVD has local maxima during such periods of stock market stress. This suggests that financial market variables such as GVD may be better at reflecting discount rate variation than are purely macroeconomic variables, not only because they are available in real-time, but also because they respond to periods of great uncertainty, where adverse outcomes may not be eventually realized.

Figure 1 also reveals two outliers in $G V D_{t, 1}^{250}$ in 1963 and 1972. These outliers are related to the creation of the NASDAQ and the AMEX stock exchanges. These events lead to a drop in $G V D$ as the addition of data from these new exchanges to the CRSP database increases the total market capitalization of the market. Rather than making ad-hoc adjustments to $G V D$ to reflect these events, we leave the GVD series unchanged and show in Section 4.1 that GVD's forecasting performance is robust to excluding these events. 


\section{$3.2 \quad$ In-sample forecasting}

We run the following forecasting regression:

$$
f_{t+\Delta t}=\alpha+\beta \times \text { Predictor }_{t}+\varepsilon_{t+\Delta t}
$$

where $f_{t+\Delta t}$ is one of the following: the excess return of the value-weighted market portfolio from $C R S P, G D P$ growth, investment growth, and excess returns of five-year Treasury bond. Returns on the five-year Treasury bond are monthly, from month $t$ to $t+1$, while the other three variables are quarterly, from month $t$ to $t+2$. All predictor variables are known prior to the start of month $t$.

The predictor variables are described in Panel A of Table 1. We follow Rapach, Strauss, and Zhou (2010) in estimating this regression with non-overlapping returns. This is important because Ang and Bekaert (2007) show that the evidence of predictability with overlapping returns depends crucially on the choice of standard errors in forecasting regressions. (We use Newey-West standard errors with 3 lags for our non-overlapping quarterly return regressions.) Also, although longer horizon regressions help in understanding economic significance of predictability, they do not help in establishing its statistical significance (see Cochrane (2001)). We therefore focus on non-overlapping returns in this section, as they are the cleanest setup in terms of statistical tests. We examine $G V D$ 's ability to forecast market returns over both monthly and annual horizons and also perform robustness tests such as alternative specifications for standard errors in Section 4.1 .

Table 2 shows the results of the regression above. Overall, GVD is the only variable that significantly forecasts all four series. Both versions of $G V D, G V D^{250}$ and $G V D^{500}$ are statistically significant in forecasting all four variables. Since both versions of $G V D$ are highly correlated, we focus our discussion on $G V D^{250}$ and only discuss results for $G V D^{500}$ if they are different from $G V D^{250}$. The next best predictors in terms of the number of series forecasted are the default spread and $C A Y$ each of which predicts two of the four series. The default spread predicts GDP growth and investment growth but does not predict market returns. $C A Y$ predicts bond and stock returns but does not predict the macroeconomic series. The other variables predict only one of the four series. 
The results in the first column of this table indicate that $G V D^{250}$ is a significant predictor of market excess returns, with an $R^{2}$ of $3.3 \%$. Campbell and Thompson (2008) present a simple metric to gauge the economic significance of return predictability: the increase in expected returns of a mean-variance investor from observing the predictor variable. Using this metric, a quarterly $R^{2}$ of $3.3 \%$ results in an increase in expected returns of $2.8 \%$ per year for an investor with a risk aversion coefficient of $5 .^{10}$ The $R^{2} \mathrm{~s}$ of $G V D^{250}$ 's forecasting regressions for market returns are generally higher than those of regressions that use the benchmark variables. The only exception is $B M$ from Pontiff and Schall (1998). ${ }^{11}$

$G V D^{250}$ predicts $G D P$ and investment growth with $R^{2} \mathrm{~s}$ of $1.3 \%$ and $6.9 \%$ respectively. These results are consistent with the theoretical motivation underlying the construction of $G V D$, since the Bernanke and Gertler (1989) model predicts that investment will decline following an increase in credit constraints. These results are also consistent with the intuition that market expected returns are higher when $G D P$ growth is expected to be low, since $G V D$ is positively correlated with future market returns and negatively correlated with future GDP growth. The default spread is the only benchmark variable that predicts GDP growth and the default and term spreads predict investment growth.

Finally, $G V D^{250}$ also predicts an increase in bond expected returns, consistent with it capturing time variation in discount rates that impacts both bond and stock returns. This is consistent with early research (e.g. Campbell (1987) and Fama and French (1989)) that finds that the same variables predict stock and bond returns. However, besides $G V D$, in our updated sample, only $C A Y$ succeeds in predicting both stock and bond returns.

\subsection{Out-of-sample forecasting}

Goyal and Welch (2008) argue that it is important to examine whether models forecast out-ofsample for two reasons. First, out-of-sample regressions allow us to investigate whether forecasting

\footnotetext{
${ }^{10}$ Note that although investor utility increases, the increase is less than that implied by just the increase in expected returns, since there is also an increase in volatility due to greater investment in the risky asset.

${ }^{11}$ The results in this panel for the benchmark variables are, in general, consistent with those in Goyal and Welch (2008), except for the results related to $C A Y$, where our $R^{2}$ s are lower. However, we find similar results using $C A Y$ as those in Goyal and Welch (2008) if we use the same period that they do.
} 
relationships are stable over time, and second, they also help determine whether an investor could have used these relationships profitably in real-time. Table 3 reports results for out-of-sample predictions for the four independent variables using $G V D$ and each of the benchmark variables in univariate predictions. These are based on expanding window estimations, with the evaluation period starting in 1975:1 and then rolling forward quarterly for all series except for the monthly bond return series, which rolls forward monthly. We choose 1975 as our initial start date so that we have at least 20 years for the initial estimation of all predictive regressions and to eliminate any effect that the 1973-1974 oil crisis might have had in the out-of-sample forecasting. We report the out-of-sample $R^{2}$ as constructed in Campbell and Thompson (2008). The out-of-sample $R^{2}$ for variable $i$ in Table 3 is given by OOS $R_{i}^{2}=1-\sum_{t=t O O S}^{T_{i}}\left(R_{t}-\widehat{R}_{i, t}\right)^{2} / \sum_{t=t O O S}^{T_{i}}\left(R_{t}-\bar{R}_{t}\right)^{2}$, where $T_{i}$ is one quarter (month) after the end of the sample of predictor variable $i$ for the quarterly (monthly) forecasting horizon, $\widehat{R}_{i, t}$ is the forecasted market returns based on variable $i, \bar{R}_{t}$ is the mean of the equity premium from the beginning of the sample until $T_{i}-1$, and $t O O S$ is 1975:1. Section 4.2 shows that the forecasting ability of $G V D$ for the market is robust to alternate start dates. We follow Goyal and Welch (2008) in using the McCracken (2007) MSE-F to evaluate statistical significance of out-of-sample predictive ability.

Table 3 shows that $G V D$ is a far better out-of-sample predictor than any of the benchmarks. $G V D^{250}$ forecasts three of the four series out-of-sample, and $G V D^{500}$ forecasts all four. In particular $G V D^{250}$ forecasts market returns, bond returns, and investment growth, with significant out-ofsample predictive ability, and $G V D^{500}$ forecasts these series as well as GDP growth. The next best predictor is the default spread that predicts two of the four series (GDP growth, investment growth). However, the default spread does not predict market returns.

$G V D^{250}$ 's out-of-sample $R^{2}$ for market returns is $6.4 \%$ and none of the benchmarks have positive out-of-sample $R^{2}$ in predicting market returns. GVD predicts monthly bond returns with an OOS $R^{2}$ of $0.4 \%$. Of the benchmark variables, only the term spread has positive OOS $R^{2}(0.2 \%)$. Evidence for $G V D$ 's ability to predict $G D P$ growth out-of-sample is mixed, with $G V D^{500}$ exhibiting significant predictive ability, but $G V D^{250}$ not significantly predicting $G D P$ growth. Both versions of $G V D$ successfully predict investment growth with OOS $R^{2}$ of $9.0 \%$ for $G V D^{250}$ and $8.0 \%$ for $G V D^{500}$. In 
the set of benchmark predictors, only the default spread has positive OOS $R^{2}(11.2 \%)$.

Overall, the results in this section are consistent with the hypothesis that $G V D$ captures timevariation in business conditions and therefore predicts time-variation in discount rates across a wide range of assets.

\section{A detailed examination of market return prediction}

In this section, we provide a detailed analysis of $G V D$ 's ability to predict market returns. There is a long literature that highlights statistical issues related to aggregate stock market return predictability. We examine whether $G V D$ 's ability to predict market returns is robust to these critiques, as well as other possible critiques specific to $G V D$. Section 4.1 examines in-sample prediction of market returns, while Section 4.2 examines out-of-sample prediction.

\subsection{Predicting market returns in-sample}

Table 4 reports results of regressions predicting market excess returns with $G V D$. Panel A shows that $G V D$ 's statistical significance in forecasting quarterly market returns is robust to alternative specifications of standard errors. We report Ordinary Least Squares (OLS), Stambaugh biascorrected (coefficients and standard errors) as well as Newey-West standard errors. We use the Amihud and Hurvich (2004) method to correct for the Stambaugh bias. The results in this panel reveal that there is only a small difference between the point estimates and the standard errors obtained with OLS compared to those obtained with the Stambaugh correction. This contrasts strongly with the results in Stambaugh (1999) using dividend-yield as the equity premium predictor. To understand the difference, note that this bias is due to the fact that $E\left[\varepsilon_{t+\Delta t} \mid y_{t+\Delta t}, y_{t}\right] \neq 0$ in the regressions $R_{t+\Delta t}=\alpha+\beta \times y_{t}+\varepsilon_{t+\Delta t}$ and $y_{t+\Delta t}=\gamma+\rho \times y_{t}+v_{t+\Delta t}$, where $y_{t}$ is either the dividend-yield or $G V D_{t, 1}^{250}$. The relatively large bias in the forecasting regression when dividendyield is the predictor is because $\rho$ is relatively large and variations in the dividend-yield are mostly due to variations in prices rather than in dividends, hence $E\left[\varepsilon_{t+\Delta t} \mid y_{t+\Delta t}, y_{t}\right]$ is further away from zero. On the other hand, $G V D$ is not as persistent as aggregate dividend-yield, and variations in 
$G V D$ are due to variations in both the market-price level and the valuations of large firms, thereby reducing the bias considerably.

Panel B of Table 4 shows the results of the forecasting regression above for different sample periods. Goyal and Welch (2008) note that many of the equity premium forecasting regressions commonly described in the literature are not robust to different sample periods. We therefore look to see if this is the case with $G V D$ and find that GVD's forecasting power for the early sample period (1927:1 to 1955:2) is weaker than that for later periods. The coefficient on GVD in the early sample period is borderline insignificant with a t-statistic of 1.43 and a p-value of $15 \%$, while the $R^{2}$ is $2.5 \%$ compared with $6.8 \%$ and $3.8 \%$ for the periods from $1955: 3$ to $1983: 3$ and $1983: 4$ to $2011: 4$, respectively. The improvement in the forecasting ability of $G V D$ over time is perhaps related to the change in the sample composition of publicly listed firms documented by Fama and French (2004). Over the later part of the sample, smaller, less profitable firms have been able to list on public equity markets. The valuations of these firms are likely to be more sensitive to aggregate business conditions, thereby improving the performance of $G V D$ in capturing discount rate variation.

Panel C analyzes the results of monthly and annual forecasting regressions with quarterly overlap to understand the forecasting power of $G V D$ across horizons. We find that $G V D^{250}$ forecasts well across horizons, with significant coefficients at monthly and annual forecasting horizons. Moreover, the $R^{2} \mathrm{~s}$ of the annual forecasting regressions (around $7 \%$ ) are economically meaningful in the context of predicting market returns.

Panel C also displays the results of using $G V D_{t, 1}^{500}$ instead of $G V D_{t, 1}^{250}$ as the predictive variable, in monthly, quarterly as well as annual (with quarterly overlap) forecasting regressions. The results in this panel reveal that $G V D^{500}$ 's forecasting performance is somewhat better than that of $G V D^{250}$. In all cases, the results are broadly consistent with those obtained using $G V D_{t, 1}^{250}$ as the independent variable, except that all three specifications have slightly higher $R^{2} \mathrm{~s}$ with $G V D^{500}$ as compared with $G V D^{250}$. Overall, the results in Panel C indicate that the in-sample forecasting power of $G V D$ is robust to changes in the cut-off point used to define $G V D$ and to changes in the forecasting horizon.

Panel D presents an analysis of the robustness of GVD's forecasting power. To do this, we estimate different variations of the regression forecasting quarterly market excess returns. The 
first two specifications explore robustness to the inclusion of data from new exchanges. In the first year of the NASDAQ and the AMEX, the denominator of GVD increases substantially, as the capitalization of the overall market increases with the inclusion of new firms; however, the numerator is unaffected, leading to drops in $G V D$. The first specification includes a dummy variable (NEWEX) that has a value of one in the years in which NASDAQ and AMEX stocks are included in the CRSP database. The next specification excludes the two years in which these exchanges are included in the CRSP universe. The coefficient on GVD is virtually unaffected across these specifications. Specification "Ex-1970s" excludes the 1970s to examine the importance of the oil shocks, and specification "Ex-Internet" ends the sample in 1997:1 to remove the influence of the Internet period. These specifications show that GVD's forecasting ability is not driven by these influential periods. Specification "FF" adds returns on the three Fama-French factors, the market, $H M L$, and $S M B$ over the prior year. The annual horizon is chosen to mimic the period used in computing $G V D$. We include the market to examine whether persistence in market returns (as in Connolly and Stivers (2003)) or lead-lag relations between small and large stocks (as in Lo and MacKinlay (1990)) drives our results. The coefficient on GVD is unaffected-and in fact increases slightly-in this specification and none of the annual returns on the Fama-French factors are significant. Finally, we skip a quarter between measuring $G V D$ and forecasting returns: $G V D$ is computed from month $t-12$ to $t-1$, and market returns are from $t+2$ to $t+5$, skipping a quarter. This provides another method of ruling out the hypothesis that lead-lag effects or other microstructure biases affect our results. The coefficient on GVD drops from 0.76 to 0.55 , but retains its statistical and economic significance in this specification. ${ }^{12}$

Overall, these regressions show that the forecasting power of $G V D$ is robust: $G V D$ remains a significant predictor of market excess returns in all specifications. $G V D$ 's forecasting power is robust to alternate definitions for $G V D$, monthly and annual horizons, and is not due to the inclusion of new exchanges in the CRSP universe, the oil crisis, the internet period, or lead-lag relations between large and small stock returns.

As another test of $G V D$ 's forecasting power for aggregate stock market returns, we analyze

\footnotetext{
${ }^{12}$ In unreported tests, we find that $G V D$ is significant in predicting quarterly market returns even after skipping up to three quarters, though the coefficients diminish in magnitude.
} 
whether $G V D$ merely summarizes the information that is already contained in predictor variables that are traditionally used in the literature. To do so, we run multivariate, in-sample, quarterly, non-overlapping regressions of aggregate stock market returns on our set of benchmark predictors and $G V D$. The results of these regressions are in Table 5. We examine three groups of predictor variables: interest rates, valuation ratios, and macroeconomic variables. We also combine these predictors into two "Kitchen-sink" regressions. The first one contains all variables for which we have a long sample of data (1927:2 onwards) and the second contains all variables, thereby shortening its sample (1952:2 onwards). The hypothesis that the coefficient on $G V D$ is equal to zero is rejected at the usual significance levels in all regressions in Table 5. The coefficient on $G V D$ changes very little across specifications as well. These results confirm that $G V D$ contains information relevant for forecasting aggregate returns that is not in the usual predictors in the literature. ${ }^{13}$

\subsection{Predicting market returns out-of-sample}

To analyze GVD's out-of-sample forecasting power, we follow the Goyal and Welch (2008) methodology. Specifically, for each quarter $(T)$, we calculate $\Delta S S E_{T}=\sum_{t=t O O S}^{T}\left(R_{t}-\bar{R}_{t}\right)^{2}-\sum_{t=t O O S}^{T}\left(R_{t}-\right.$ $\left.\widehat{R}_{t}\right)^{2}$ where $\bar{R}_{t}$ is the mean of the equity premium from the beginning of the sample (1927:1) until $T-1, \widehat{R}_{t}$ is the equity premium forecasted with an OLS regression of aggregate market returns on $G V D$, which is estimated with the sample from 1927:1 to $T-1$, and $t O O S$ is the beginning of the out-of-sample period.

Figure 2 plots $\triangle S S E_{T}$ as a function of time $T$, for quarterly predictions in Panel $\mathrm{A}$, and annual predictions (with quarterly overlap) in Panel B. We set tOOS=1947:1, allowing for a 20-year initial training sample. Negative values of $\triangle S S E_{T}$ in this figure imply that $G V D$ is worse than the running-mean equity premium in forecasting market excess returns out-of-sample. On the other hand, positive values of $\triangle S S E_{T}$ imply that $G V D$ has a better forecasting performance than the running-mean equity premium. This figure shows that the out-of-sample forecasting performance of $G V D$ has been better than that of the running mean since the 1970s. Note that in 1962 the

\footnotetext{
${ }^{13}$ In unreported results we find the $G V D$ 's forecasting performance is unaffected by controlling for two other variables evaluated by Goyal and Welch (2008), net equity expansion (ntis) and the cross-sectional premium (csp) from Polk, Thompson, and Vuolteenaho (2006).
} 
forecasting performance of $G V D$ deteriorates substantially due to the inclusion of AMEX stocks in the CRSP universe. On the other hand, the 1973-1974 oil crisis along with the inclusion of NASDAQ stocks in 1972 improves GVD's forecasting performance. We therefore investigate the statistical significance and robustness of our out-of-sample results to different start dates for the evaluation period in Table 7.

Table 7 reports out-of-sample $R^{2} s$ for evaluation periods beginning every decade from 1947:1 to 1987:1. Although out-of-sample $R^{2}$ s vary across periods, they are uniformly positive for both $G V D^{250}$ and $G V D^{500}$ in quarterly predictions in Panel A and annual (with quarterly overlap) predictions in Panel B. In order to evaluate the statistical significance of these results, we report p-values for the MSE-F test of equal predictive ability in McCracken (2007). The null hypothesis in this test is that two nested models have equal predictive ability out-of-sample, and the one-sided alternative is that the more complex model has better predictive ability. We test whether $\bar{R}_{t}$ (the historical market mean) and $\widehat{R}_{t}$ (the prediction from $G V D$ ) have equal predictive ability for market excess returns. Both out-of-sample forecasts utilize expanding-window estimation periods. The p-values in Panel A are asymptotic values from McCracken (2007). P-values in Panel B are from a bootstrap procedure, similar to that in Goyal and Welch (2008), except that we use a block bootstrap to account for the quarterly overlap in annual market returns. ${ }^{14}$ We can reject the hypothesis that $G V D$ and the running-mean have equal predictive ability, in favor of $G V D$, for all specifications.

\section{The theoretical underpinnings of $G V D$}

In this section, we dig deeper to understand the source of $G V D$ 's ability to forecast market returns, and test whether $G V D$ 's forecasts are consistent with rational time-variation in discount rates related to changes in aggregate business conditions. ${ }^{15}$ First, in Section 5.1, we decompose GVD

\footnotetext{
${ }^{14}$ We use a block length of 4 , which is of the order of magnitude of $n^{0.25}$ (see Hall, Horowitz, and Jing (1995)). We get similar results for block lengths between 1 and 8 .

${ }^{15}$ In unreported results, we show that the payouts of large firms covary much less with aggregate consumption growth than do those of small firms. This difference is large enough that GVD has a large correlation (over $80 \%$ ) with the representative agent's risk aversion in a calibration of the Menzly, Santos, and Veronesi (2004) model. Note that the difference in payouts likely arises due to the difference in the ability to access external finance during economic downturns. For brevity, we do not report these results. They are available from the authors on request.
} 
into two components to understand whether its predictive ability comes solely from one of the components. In Section 5.2 we examine the predictive ability of $G V D$ for GDP and investment growth as well as whether $G V D$ 's forecasting ability for market returns varies across the business cycle. Finally in Section 5.3 we examine $G V D$ 's ability to forecast returns on other assets: bonds with different maturities, and portfolios formed from sorts on size and book-to-market.

\subsection{The components of $G V D$}

$G V D$ has a simple definition: the change in valuation of the largest 250 firms relative to the aggregate market over a 12 month-period. This simple definition admits a decomposition. As described in Section 1, GVD can be written as the sum of two components. The first component, GVD $O L D$, is the difference in returns (excluding dividends) of the largest 250 firms and the entire market. The second component, $G V D_{N E W}$, is the difference between the growth in the capitalization of the largest 250 firms due to new capital raised and the growth in the entire market capitalization due to capital raising. Net new capital is calculated implicitly. For example, net new capital for the largest 250 firms is the aggregate market capitalization at time $t$ for firms that were the 250 largest at the end of month $t-12$, minus the sum of the market capitalizations of these 250 firms at the end of $t-12$ grown by their respective returns in the period excluding dividends.

In this section, we test if $G V D$ 's forecasting ability arises solely from one of these components or whether both components are required. This question is important in understanding the mechanism underlying $G V D$ 's forecasting power. Moreover, if only one of the components is important, we can refine $G V D$ to reflect only that component. Note that prior research suggests that both components should predict market returns. Positive values for $G V D_{O L D}$ mean that small firms have had lower returns than large firms, potentially indicating that the market expects access to external finance to be more difficult; similarly, high values for $G V D_{N E W}$ imply that small firms have raised less net

new capital as compared with large firms, consistent with external finance becoming more expensive for these firms.

Table 6 shows that both components are important in predicting quarterly market returns. Each component is significant when both are used together to predict market returns. Also, imposing 
equal coefficients, as we implicitly do when using $G V D$, does not hurt predictive power. A formal test of the hypothesis that the coefficients of $G V D_{O L D}$ and $G V D_{N E W}$ are equal is not rejected (pvalue 0.24 ). Also, the $R^{2}$ is $3.3 \%$ with $G V D$ and $3.5 \%$ when both components are used separately. The coefficient on each component in univariate forecasting regressions is not as large as when both components are used together. The coefficient on $G V D_{N E W}$ rises from 0.67 to 0.92 when $G V D_{O L D}$ is added. Similarly, the coefficient on $G V D_{O L D}$ goes from 0.36 to 0.65 when $G V D_{N E W}$ is added. Overall, these results indicate that the functional form of $G V D$ is appropriate.

In the final specification, we find that the coefficient on $S M B$ is insignificant when used to predict market returns by itself. Note that although $S M B$ is correlated with $G V D_{O L D}$, it does not have significant forecasting performance by itself, while $G V D_{O L D}$ does. This suggests that focusing on the largest stocks like $G V D$ does, helps in predicting market returns relative to $S M B$ which is based on the median NYSE firm. The final specification shows that $S M B$ significantly predicts market returns when we also include the capital raising component of $G V D, G V D_{N E W}$. This reinforces the importance of using both components in forecasting market returns. This result may explain why prior research on $S M B$ has not uncovered its forecasting ability for market returns.

One intuitive explanation for these results is that both components of $G V D$ capture different aspects of the same underlying phenomenon and therefore reinforce each other. When small firms have lower returns than large firms it possibly indicates that the market expects a period of economic stress, with costly external capital. When this is combined with lower net capital raised by small firms relative to large firms, this further confirms that capital is costly and that the low relative returns are not because of other reasons.

Another interesting feature of $G V D_{O L D}$ and $G V D_{N E W}$ is their correlation structure. Table 1 shows that these two variables are negatively correlated $(\rho=-28 \%)$. This negative correlation is the econometric reason for the increase in coefficients going from univariate to bivariate prediction regressions. The fact that both components forecast market returns in the same direction, suggests that discount rate news affects them in the same way. Therefore, the negative correlation must arise from differing effects of cash flow shocks. One economic mechanism by which cash flow shocks could affect these components differently is via internally generated cash flows. Suppose large firms have 
unexpectedly positive cash flow news, leading to positive contemporaneous returns and therefore an increase in $G V D_{O L D}$. For a given distribution of projects, this means that they will have more internally generated funds and therefore have a smaller need to raise external capital, leading to a decrease in $G V D_{N E W}$.

\subsection{Cyclical variations and $G V D$}

We have shown in Section 3.2 that GVD significantly predicts GDP growth and investment growth in univariate forecasting regressions, in this section we examine whether $G V D$ 's forecasting ability survives additional controls. In particular, the Bernanke and Gertler (1989) model implies that an increase in $G V D$ is correlated with greater difficulty in accessing external finance and should predict lower aggregate investment even when we control for current economic conditions. In addition, the Bernanke and Gertler (1989) model implies that the financing constraints bind in recessions.

We therefore examine whether $G V D$ 's effect on market returns is asymmetric in recessions versus expansions.

Table 8, Panel A shows the regressions predicting GDP growth and investment growth using $G V D$. GVD predicts both variables both in univariate regressions and in multivariate regressions with additional controls. These controls include lagged values of the series being forecasted, as well as the term-spread and default spread and lagged annual returns on the market. The sign of the coefficient on $G V D$ is negative, consistent with our motivation. A high value of $G V D$ indicates that large firms have gained market share at the expense of small firms, signifying an economic downturn with higher cost of capital. Finally, higher costs of capital as proxied by higher $G V D$ also predict lower aggregate investment.

The Bernanke and Gertler (1989) model also implies that credit constraints bind in during periods of low economic growth. Therefore $G V D^{\prime}$ s forecasting ability should be higher during such times. We test this hypothesis using a dummy variable, LowGDP. LowGDP is one if the prior quarter's (quarter $t$ when predicting returns for quarter $t+1$ ) GDP growth is below its time-series median and zero otherwise. We include LowGDP, as well as an interaction of LowGDP with GVD as predictive variables to forecast the four independent variables we consider in this paper. We find 
that the interaction is of the expected sign for all four variables; and is statistically significant for three of the four, and marginally insignificant for the remaining one. In particular, the coefficient for predicting market returns on $G V D$ is 0.264 (t-value 1.26) and that on the interaction of $G V D$ with LowGDP is 1.113 (t-value 2.99). That is in periods of low GDP growth, the impact of a change in $G V D$ on future market returns is 1.377 , or more than five times the coefficient on $G V D$ when GDP growth is above its median. Thus, expected market returns are not sensitive to changes in $G V D$ in good times, but are sensitive to changes in GVD in bad times. This asymmetry is predicted by the Bernanke and Gertler (1989) model, since financing constraints bind during downturns in the model. Similarly, the interaction term is significant in predicting GDP and investment. In regressions predicting five year bond returns, the coefficients on the interaction are large in magnitude relative to the coefficient on $G V D$ but have a t-statistic of 1.46. Overall, these results strongly support the hypothesis that $G V D$ 's forecasting ability is more pronounced in recessions rather than expansions.

\subsection{Forecasting other asset returns}

In this section, we examine the ability of $G V D$ to predict returns on bonds and the cross-section of stock returns. Fama and French (1989) and Campbell (1987) argue that discount rate variation related to aggregate business conditions should be visible across assets and therefore variables that predict bond returns, such as the term spread, should also predict stock returns. These tests also allow us to confirm that $G V D$ predicts discount rate shocks - for example, if the variations in $G V D$ were solely due to differences in cash-flow news for small and large firms, $G V D$ would not predict bond returns.

We first examine the ability of $G V D$ to predict bond returns. We focus on excess returns of bond indices consisting of bonds with maturity of 90 days, one year, two years, five years and ten

years. All returns are in excess of the 30 day risk-free rate. We expect that longer maturity bonds are more sensitive to discount rate shocks, since they have higher durations. Therefore, if $G V D$ captures discount rate variation, the excess returns of long maturity bonds should have a positive loading on $G V D$. Moreover, the loadings on $G V D$ should increase as the maturity of the bond increases. 
Table 9, Panel A shows the results of regressions of monthly bond returns of the different maturities described above on $G V D$, along with controls. The controls we include are the lagged returns on the bond being predicted and the term-spread. Panel A shows that GVD significantly predicts excess returns for bonds with maturity greater than 90 days. Moreover, the coefficients on GVD increase monotonically as the maturity of the bonds increases. ${ }^{16}$

Panel B examines regressions predicting quarterly non-overlapping returns of 25 size and book-tomarket sorted portfolios. There are two reasons to examine whether $G V D$ forecasts these portfolios and the sensitivity of these portfolios to GVD. First, in the Bernanke and Gertler (1989) model, credit constraints impact investment through the value of collateral. Bernanke and Gertler (1989) note that firms with a high fraction of assets that are difficult to collateralize, such as human capital, will find it harder to access external capital during downturns. This suggests that small growth firms whose market valuations are driven more by future growth opportunities, will be more sensitive to changes in $G V D$, as compared to large value firms that have a greater fractions of assets in place. Second, Campbell and Vuolteenaho (2004) and Lettau and Wachter (2007) show that since growth stocks have longer duration cash flows than value stocks, their returns are more sensitive to discount rate shocks.

Table 9, Panel B shows that GVD coefficients increase within each size quintile, as we move from value to growth. Similarly, coefficients on $G V D$ increase as we move from large to small, within each book-to-market quintile. The difference in coefficients on $G V D$ between the largest and smallest quintiles, within each book-to-market quintile, is always negative; three of the five differences are statistically significant. Similarly, the difference between the coefficients on GVD for the most value and the most growth quintile, within each size quintile, is also always negative; four of the five differences are statistically significant. Thus, as expected, small growth stocks are most sensitive to changes in $G V D$. Note that since large stocks are less volatile than small stocks, the $R^{2}$ in regressions predicting returns of the largest growth portfolio is amongst the highest of the 25 size and book-to-market sorted portfolios at almost 4\%. This fact underlines GVD's economic relevance: $G V D$ 's success in predicting value-weighted market returns stems from its ability to

\footnotetext{
${ }^{16}$ In untabulated tests we find that these results are robust to 1) running univariate forecasting regressions 2) excluding the "Volcker period" (1979-1983).
} 
predict the largest stocks in the economy.

Panel $\mathrm{C}$ examines whether $G V D$ is able to predict $H M L$ and $\mathrm{SMB}$, the Fama-French factors that reflect size and value premiums. We predict quarterly arithmetic returns on $S M B$ and $H M L$ using $G V D$ and controlling for lagged quarterly returns on the respective factor. We find that the coefficient on $G V D$ is statistically significant in predicting both $S M B$ and HML. Consistent with the results on the size and book-to-market portfolios, an increase in $G V D$ is positively correlated with next quarter's $S M B$ and negatively correlated with next quarter's $H M L$ returns. This is consistent with the result in Campbell and Vuolteenaho (2004) that growth stocks have higher betas to discount rate news. Campbell and Vuolteenaho (2004) explain the positive risk premium to $H M L$ by noting that value stocks have higher betas to cash-flow news, and the permanent cash-flow news component carries a higher risk premium than the transitory discount rate news component.

\section{Conclusion}

We show that the relative valuation of small and large firms is a real-time indicator of aggregate economic conditions. Large firms are able to withstand recessions better than small firms, and their valuations reduce by less during such times. This is consistent with the implications of the Bernanke and Gertler (1989) model, which implies that following adverse economic shocks, the decline in value of small firm balance-sheets makes it harder for small firms to access external finance. We show that the relative valuation of small and large firms predicts market returns, bond returns, GDP growth, investment growth, $H M L$ and $S M B$.

In some ways, this paper returns to the roots of the market predictability literature. Fama and French (1989) argue that time-variation in discount rates is related to changes in aggregate business conditions. These time-varying discount rates apply to both stock and bond markets, and therefore simple variables such as term and default spreads should predict both stock and bond returns. Subsequent research has proposed additional tests to ensure that the predictability is real. Similar to early research, we find that a single variable related to aggregate business conditions 
predicts both stock and bond returns as well as GDP and investment growth. We take the recent critiques of market predictability seriously and apply the proposed new tests, including focussing on (quarterly) non-overlapping returns, correcting for the Stambaugh bias, and testing whether predictability survives out-of-sample.

$G V D$ 's out-of-sample performance in forecasting aggregate stock returns is impressive. We find that all the usual predictors of quarterly aggregate stock market returns have negative out-ofsample $R^{2}$ s, while $G V D$ is the only predictor that has positive out-of-sample $R^{2}$. In fact, GVD's out-of-sample $R^{2}$ is not only positive but is also economically highly significant. We also show that consistent with our motivation, GVD predicts aggregate investment growth and returns on bonds and size and book-to-market sorted portfolios. These tests confirm that GVD's forecasting ability is real and not the result of data-mining. We also show that $G V D$ 's predictive ability is not due to information contained in traditional variables, such as $S M B$ and net payout. Thus, $G V D$ is likely to be a useful and novel instrument in tests of conditional asset pricing models.

Our results are consistent with the hypothesis that expected returns vary with business cycles. McLean and Pontiff (2012) find that predictable patterns in the cross-section of stocks diminish once they are in the public domain, consistent with the possibility that these patterns are not due to compensation for risk, and that arbitrageurs act against mispricing once they are aware of it. Consequently, it is possible that the only test that can reveal whether the predictability that we document is due to time-variation in discount rates related to business cycles, is the test of time. However, $G V D$ forecasts bond returns, GDP growth, aggregate investment growth as well as market returns and is grounded in business cycle research. Hence, we think that it is likely that GVD's forecasting power is due to risk. 


\section{Appendix A - Decomposing $G V D$}

In this appendix we show that $G V D_{t, \Delta t}^{m}$ can be decomposed in two components. One component is the difference in ex-dividend returns of the portfolio with $m$ stocks and of the market portfolio. The second component is the difference in capital raised by the $m$ largest firms in $t-\Delta t$ and the capital raised by the rest of the market. To see this note that:

$$
G V D_{t, \Delta t}^{m}=\ln \left(\frac{P_{m, t}}{P_{M, t}}\right)-\ln \left(\frac{P_{m, t-\Delta t}}{P_{M, t-\Delta t}}\right)
$$

Where $P_{m, t}$ is equal to sum of the market capitalization at time $t$ of the $m$ largest firms in the market portfolio at time $t-\Delta t$ and $P_{M, t}$ is the sum of the market capitalization at time $t$ of all the firms in the market portfolio. $G V D_{t, \Delta t}^{m}$ can be rewritten as:

$$
G V D_{t, \Delta t}^{m}=\ln P_{m, t}-\ln P_{m, t-\Delta t}-\left(\ln P_{M, t}-\ln P_{M, t-\Delta t}\right)
$$

Note that $P_{j, t}=\sum_{i=1}^{K_{j}}\left(N_{t-\Delta t}^{i}+\Delta N_{t}^{i}\right) p_{t}^{i}, j=m$ or $M$, where $N_{t-\Delta t}^{i}$ is the number of shares of the $\mathrm{i}^{t h}$ firm in the portfolio, $\Delta N_{t}^{i}$ is change in the number of shares between $t$ and $t-\Delta t, p_{t}^{i}$ is the price of the $\mathrm{i}^{\text {th }}$ firm at time $t$, and $K_{j}$ is the number of stocks in the portfolio. An algebraic manipulation of $P_{j, t}$ implies that $\ln \left(P_{j, t}\right)$ is equal to $\ln \left(\sum_{i=1}^{K_{j}} N_{t-\Delta t}^{i} p_{t}^{i}\right)$ plus $\ln \left(\sum_{i=1}^{K_{j}}\left(N_{t-\Delta t}^{i}+\Delta N_{t}^{i}\right) p_{t}^{i} / \sum_{i=1}^{K_{j}} N_{t-\Delta t}^{i} p_{t}^{i}\right)$. Substituting this expression for $P_{j, t}$ in the equation above, we get:

$$
\begin{aligned}
G V D_{t, \Delta t}^{m}= & \left(\ln \frac{\sum_{i=1}^{m} N_{t-\Delta t}^{i} p_{t}^{i}}{\sum_{i=1}^{m} N_{t-\Delta t}^{i} p_{t-\Delta t}^{i}}-\ln \frac{\sum_{i=1}^{M} N_{t-\Delta t}^{i} p_{t}^{i}}{\sum_{i=1}^{M} N_{t-\Delta t}^{i} p_{t-\Delta t}^{i}}\right)+ \\
& \left(\ln \frac{\sum_{i=1}^{m}\left(N_{t-\Delta t}^{i}+\Delta N_{t}^{i}\right) p_{t}^{i}}{\sum_{i=1}^{m} N_{t-\Delta t}^{i} p_{t}^{i}}-\ln \frac{\sum_{i=1}^{M}\left(N_{t-\Delta t}^{i}+\Delta N_{t}^{i}\right) p_{t}^{i}}{\sum_{i=1}^{M} N_{t-\Delta t}^{i} p_{t}^{i}}\right)
\end{aligned}
$$

The term within the first parentheses of the equation above is the difference between the exdividend return of the portfolio of large stocks and of the market portfolio. The term within the second parentheses is the difference between the growth due to share issuance of the portfolio of large stocks and of the market portfolio. Call $E x R_{t, \Delta t}^{j}=\ln \sum_{i=1}^{K_{j}} N_{t-\Delta t}^{i} p_{t}^{i} / \sum_{i=1}^{K_{j}} N_{t-\Delta t}^{i} p_{t-\Delta t}^{i}$ and 
$G_{t, \Delta t}^{j}=\ln \left(\sum_{i=1}^{K_{j}}\left(N_{t-\Delta t}^{i}+\Delta N_{t}^{i}\right) p_{t}^{i} / \sum_{i=1}^{K_{j}} N_{t-\Delta t}^{i} p_{t}^{i}\right)$ to write:

$$
\begin{aligned}
G V D_{t, \Delta t}^{m} & =\left(E x R_{t, \Delta t}^{m}-E x R_{t, \Delta t}^{M}\right)+\left(G_{t, \Delta t}^{m}-G_{t, \Delta t}^{M}\right) \\
G V D_{t, \Delta t}^{m} & =G V D_{O L D}+G V D_{N E W}
\end{aligned}
$$

We implement this decomposition in the data using returns excluding dividends from CRSP, $r_{t-12, t}^{x}$. We first compute the value of capital at time $t$, that existed at time $t-12, P_{j, t}^{e x i s t}$ as:

$$
\begin{aligned}
P_{j, t}^{E X I S T} & =\sum_{i=1}^{j} P_{i, t-12}\left(1+r_{i, t-12, t}^{x}\right) \\
E x R_{t, \Delta t}^{j} & =\ln \left(\frac{P_{j, t}^{E X I S T}}{P_{j, t-12}}\right)
\end{aligned}
$$

where $j=m$ or $M$. We compute $G V D_{O L D}$ from $E x R_{t, \Delta t}^{m}$ and $E x R_{t, \Delta t}^{M}$. We compute net new capital as:

$$
P_{j, t}^{N E W}=P_{j, t}-P_{j, t}^{E X I S T}
$$

where $j=m$ or $M$. We compute $G V D_{N E W}$ from $P_{j, t}^{N E W}$ and $P_{j, t}$ as described above. 


\section{References}

Amihud, Yakov, and Clifford M. Hurvich, 2004, Predictive regressions: A reduced-bias estimation method, Journal of Financial and Quantitative Analysis 39, 813-841.

Ang, Andrew, and Geert Bekaert, 2007, Stock return predictability: Is it there?, Review of Financial Studies 20, 651-707.

Bernanke, Ben, and Mark Gertler, 1989, Agency costs, net worth and business cycle fluctuations, American Economic Review 79, 14-131.

— 1990, Financial fragility and economic performance, Quarterly Journal of Economics 105, $87-114$.

— , and Simon Gilchrist, 1996, The financial accelerator and the flight to quality, Review of Economics and Statistics 78, 1-15.

Bernanke, Ben S, Mark Gertler, and Simon Gilchrist, 1999, The financial accelerator in a quantitative business cycle framework, Handbook of Macroeconomics 1, 1341-1393.

Boudoukh, Jacob, Roni Michaely, Matthew Richardson, and Michael R. Roberts, 2007, On the importance of measuring payout yield: Implications for empirical asset pricing, Journal of Finance $62,877-915$.

Caballero, Ricardo J, and Arvind Krishnamurthy, 2008, Collective risk management in a flight to quality episode, The Journal of Finance 63, 2195-2230.

Campbell, John Y., 1987, Stock returns and the term structure, Journal of Financial Economics $18,373-399$.

— , and John H. Cochrane, 1999, By force of habit: A consumption based explanation of aggregate stock market behavior, Journal of Political Economy 107, 205-251.

Campbell, John Y., and Robert R. Shiller, 1988a, The dividend-price ratio and expectations of future dividends and discount factors, The Review of Financial Studies 1, 195-228. 
— , 1988b, Stock prices, earnings, and expected dividends, Journal of Finance 43, 661-676.

Campbell, John Y., and Samuel B. Thompson, 2008, Predicting excess stock returns out of sample: Can anything beat the historical average?, Review of Financial Studies 21, 1509-1531.

Campbell, John Y., and Tuomo Vuolteenaho, 2004, Bad beta, good beta, The American Economic Review 94, 1249-1275.

Cochrane, John, 1999, New facts in finance, Economic Perspectives 23, 36-58.

— 2001, Asset Pricing (Princeton University).

— , and Monika Piazzesi, 2005, Bond risk premia, American Economic Review 94, 138-160.

Cochrane, John H., 1991, Production-based asset pricing and the link between stock returns and economic fluctuations, Journal of Finance 46, 209-237.

Connolly, Robert, and Chris Stivers, 2003, Momentum and reversals in equity-index returns during periods of abnormal turnover and return dispersion, The Journal of Finance 58, 1521-1555.

Covas, Francisco, and Walter J. Den Haan, 2011, The cyclical behavior of debt and equity finance, American Economic Review 101, 877-899.

Fama, Eugene F, and Kenneth R French, 1988, Dividend yields and expected stock returns, Journal of Financial Economics 22, 3-25.

— 1989, Business conditions and expected returns on stocks and bonds, Journal of Financial Economics 25, 23-49.

— , 1996, Multifactor explanations of asset pricing anomalies, Journal of Finance 51, 55-84.

— 2004, New lists: Fundamentals and survival rates, Journal of Financial Economics 73, $229-269$.

Ferreira, Miguel A., and Pedro Santa-Clara, 2011, Forecasting stock market returns: The sum of the parts is more than the whole, Journal of Financial Economics 100, 514-537. 
Ferson, Wayne E., Sergei Sarkissian, and Timothy Simin, 2003, Spurious regressions in financial economics, The Journal of Finance 63, 1393-1414.

Fogel, Kathy, Randall Morck, and Bernard Yeung, 2008, Big business stability and economic growth: Is what's good for general motors good for america?, Journal of Financial Economics 89, 83-108.

Gertler, Mark, and Simon Gilchrist, 1994, Monetary policy, business cycles, and the behavior of small manufacturing firms, The Quarterly Journal of Economics 109, 309-340.

Goyal, Amit, and Ivo Welch, 2008, A comprehensive look at the empirical performance of equity premium prediction, Review of Financial Studies 21, 1455-1508.

Hall, Peter, Joel L Horowitz, and Bing-Yi Jing, 1995, On blocking rules for the bootstrap with dependent data, Biometrika 82, 561-574.

Hansen, Peter. R., and Allan Timmermann, 2012, Choice of sample split in out-of-sample forecast evaluation, Working paper.

Henkel, Sam James, J Spencer Martin, and Federico Nardari, 2011, Time-varying short-horizon predictability, Journal of Financial Economics 99, 560-580.

Kelly, Bryan, and Seth Pruitt, 2012, Market expectations in the cross section of present values, Journal of Finance Forthcoming.

Kiyotaki, Nobuhiro, and John Moore, 1997, Credit cycles, Journal of Political Economy 105, 211248.

Lettau, Martin, and Sydney Lydvigson, 2001, Consumption, aggregate wealth, and expected stock returns, Journal of Finance 56, 815-849.

Lettau, Martin, and Jessica A. Wachter, 2007, Why is long-horizon equity less risky? a durationbased explanation of the value premium, Journal of Finance 62, 55-92.

Liang, Claire Y. C., R. David McLean, and Mengxin Zhao, 2011, Creative destruction and finance: Evidence from the last half century, Working paper. 
Lo, AW, and AC MacKinlay, 1990, When are contrarian profits due to stock market overreaction?, Review of Financial Studies 3, 175-205.

McCracken, Michael, 2007, Asymptotics for out-of-sample tests of granger causality, Journal of Econometrics 140, 719-752.

McLean, R. David, and Jeffrey Pontiff, 2012, Does academic research destroy stock return predictability?, Working paper.

Menzly, Lior, Tano Santos, and Pietro Veronesi, 2004, Understanding predictability, Journal of Political Economy 112, 1-47.

Perez-Quiros, Gabriel, and Allan Timmermann, 2000, Firm size and cyclical variations in stock returns, The Journal of Finance 55, 1229-1262.

Polk, Christopher, Samuel Thompson, and Tuomo Vuolteenaho, 2006, Cross-sectional forecasts of the equity premium, Journal of Financial Economics 81, 101-141.

Pontiff, Jeffrey, and Lawrence D. Schall, 1998, Book-to-market ratios as predictors of market returns, Journal of Financial Economics 49, 141-160.

Rapach, David E., Jack K. Strauss, and Guofu Zhou, 2010, Out-of-sample equity premium prediction: Combination forecasts and links to the real economy, Review of Financial Studies 23, $821-862$.

Schwert, G. William, 1990, Stock returns and real activity: A century of evidence, Journal of Finance 45, 1237-1257.

Stambaugh, Robert F., 1999, Predictive regressions, Journal of Financial Economics 54, 375-421.

Subrahmanyam, Avanidhar, and Sheridan Titman, 2012, Financial market shocks and the macroeconomy, Working paper. 


\section{Table 1: Summary statistics}

This table presents statistics for GVD $250, \mathrm{GVD}^{500}$, and our set of benchmark predictors for market excess returns. GVD ${ }^{250}\left(\mathrm{GVD}^{500}\right)$ is the change in the log weight of the largest 250 (500) firms in the aggregate market portfolio over the last 12 months. The benchmark predictors include interest rate variables, DS and TS (default and term spreads); valuation ratios, DP, CAPE, BM, CRSPNPY (dividend to price, cyclically adjusted price to earnings, book-to-market of the DJIA, and $\log$ net payout of all CRSP stocks); as well as macro variables, CAY and IK (consumption-wealth ratio, and investment-to-capital ratio). Panel A presents summary statistics. These include mean, standard deviation, minimum and maximum. Panel A also presents autocorrelations at quarterly (overlapping for GVD) and annual (non-overlapping) horizons. Panel B presents correlations between GVD ${ }^{250}$, $\mathrm{GVD}^{500}, \mathrm{GVD}_{\mathrm{OLD}}, \mathrm{GVD}_{\mathrm{NEW}}$, annual returns on the Fama-French factor, SMB12, and the benchmark predictors. $\mathrm{GVD}_{\mathrm{OLD}}$ and $\mathrm{GVD}_{\mathrm{NEW}}$ are the two components of GVD. GVD $\mathrm{OLD}_{\mathrm{O}}$ is the difference in returns on existing capital between the top 250 firms and market, and $\mathrm{GVD}_{\mathrm{NEW}}$ is the difference in net equity issuance between the top 250 firms and the market. Web addresses for the sources of each of the benchmark predictors are:

FRED: $\quad$ http://research.stlouisfed.org/fred2/

Shiller: $\quad$ http://www.econ.yale.edu/ shiller/data.htm

Goyal: $\quad$ http://www.hec.unil.ch/agoyal/

Roberts: http://finance.wharton.upenn.edu/ mrrobert/

Panel A: Summary statistics

\begin{tabular}{lccccccccc}
\hline & Start & End & Source & Mean & Std & Min & Max & $\rho 1$ Qtr $\rho 1$ Ann \\
\hline GVD $^{250}$ & $1926: 4$ & $2011: 4$ & This paper & -0.02 & 0.03 & -0.12 & 0.07 & 0.70 & 0.11 \\
GVD $^{500}$ & $1926: 4$ & $2011: 4$ & This paper & -0.02 & 0.03 & -0.14 & 0.04 & 0.73 & 0.09 \\
DS & $1926: 3$ & $2011: 4$ & FRED & 0.01 & 0.01 & 0.00 & 0.05 & 0.90 & 0.71 \\
TS & $1926: 3$ & $2011: 4$ & Shiller & 0.02 & 0.01 & -0.04 & 0.05 & 0.85 & 0.60 \\
DP & $1926: 3$ & $2011: 4$ & Shiller & -3.33 & 0.46 & -4.46 & -2.33 & 0.97 & 0.88 \\
CAPE & $1926: 3$ & $2011: 4$ & Shiller & 17.39 & 7.31 & 7.83 & 44.20 & 0.97 & 0.88 \\
CAY & $1952: 1$ & $2011: 4$ & Lettau & 0.00 & 0.02 & -0.04 & 0.04 & 0.92 & 0.72 \\
IK & $1947: 1$ & $2011: 4$ & Goyal & 0.04 & 0.00 & 0.03 & 0.04 & 0.96 & 0.73 \\
BM & $1926: 3$ & $2011: 4$ & Goyal & 0.58 & 0.26 & 0.13 & 1.44 & 0.94 & 0.84 \\
CRSPNPY & $1927: 1$ & $2010: 4$ & Roberts & -2.14 & 0.22 & -3.03 & -1.69 & 0.95 & 0.73 \\
\hline
\end{tabular}


Table 1: Summary statistics (contd.)

Panel B: Correlations

\begin{tabular}{|c|c|c|c|c|c|c|c|c|c|c|c|c|c|}
\hline & $\mathrm{GVD}^{250}$ & $\mathrm{GVD}^{500}$ & $\mathrm{GVD}_{\mathrm{OLD}}$ & $\mathrm{GVD}_{\mathrm{NEW}}$ & SMB12 & DS & $\mathrm{TS}$ & DP & CAPE & CAY & IK & $\mathrm{BM}$ & CRSPNPY \\
\hline $\mathrm{GVD}^{250}$ & 1.00 & & & & & & & & & & & & \\
\hline $\mathrm{GVD}^{500}$ & 0.92 & 1.00 & & & & & & & & & & & \\
\hline $\mathrm{GVD}_{\mathrm{OLD}}$ & 0.64 & 0.34 & 1.00 & & & & & & & & & & \\
\hline $\mathrm{GVD}_{\mathrm{NEW}}$ & 0.49 & 0.73 & -0.36 & 1.00 & & & & & & & & & \\
\hline SMB12 & -0.41 & -0.13 & -0.79 & 0.39 & 1.00 & & & & & & & & \\
\hline $\mathrm{DS}$ & 0.12 & 0.12 & -0.01 & 0.16 & 0.16 & 1.00 & & & & & & & \\
\hline TS & -0.02 & 0.08 & -0.16 & 0.16 & 0.21 & 0.31 & 1.00 & & & & & & \\
\hline DP & 0.14 & 0.13 & -0.07 & 0.24 & 0.02 & 0.40 & -0.10 & 1.00 & & & & & \\
\hline CAPE & -0.10 & -0.15 & 0.15 & -0.29 & -0.12 & -0.36 & -0.07 & -0.87 & 1.00 & & & & \\
\hline CAY & 0.12 & 0.11 & 0.16 & -0.05 & -0.14 & -0.14 & 0.14 & 0.09 & 0.02 & 1.00 & & & \\
\hline IK & -0.03 & -0.08 & 0.18 & -0.27 & -0.01 & -0.08 & -0.46 & -0.25 & 0.35 & -0.02 & 1.00 & & \\
\hline $\mathrm{BM}$ & 0.11 & 0.17 & -0.16 & 0.32 & 0.17 & 0.47 & -0.07 & 0.82 & -0.84 & -0.14 & -0.05 & 1.00 & \\
\hline CRSPNPY & 0.20 & 0.24 & -0.08 & 0.34 & 0.14 & 0.31 & 0.07 & 0.81 & -0.81 & -0.04 & -0.39 & 0.71 & 1.00 \\
\hline
\end{tabular}


Table 2: Predicting stock returns, bond returns, GDP and investment growth in-sample

This table presents results of regressions of the type:

$$
\mathrm{Y}_{\mathrm{t}+\Delta \mathrm{t}}=\mathrm{a}+\mathrm{b} \text { Predictor }_{\mathrm{t}}+\varepsilon_{\mathrm{t}+\Delta \mathrm{t}}
$$

The dependent variables are: (1) Quarterly arithmetic excess returns of the CRSP value-weighted index over the monthly risk-free rate, (2) Monthly excess returns of a 5-year Treasury bond portfolio over the risk-free rate, (3) Quarterly real GDP Growth (GDPG), (4) Quarterly real Private Fixed Investment Growth (PFIG). All regressions have non-overlapping dependent variables. The predictor variables include interest rate variables, DS and TS (default and term spreads); valuation ratios, DP, CAPE, BM, CRSPNPY (dividend to price, cyclically adjusted price to earnings, book-to-market of the DJIA, and $\log$ net payout of all CRSP stocks); as well as macro variables, CAY and IK (consumption-wealth ratio and investment-to-capital ratio). These are described in greater detail in Table 1. All standard errors are Newey-West (with 3 lags). The symbols $* * *, * *$, and * represent statistical significance at the $1 \%, 5 \%$ and $10 \%$ levels, respectively.

\section{Quarterly MKTRF returns}

\begin{tabular}{lllll} 
& \multicolumn{1}{c}{$\mathrm{a}$} & \multicolumn{1}{c}{$\mathrm{b}$} & \multicolumn{1}{c}{$\mathrm{R}^{2}$} & $\mathrm{~N}$ \\
\cline { 2 - 5 } $\mathrm{GVD}^{250}$ & $0.038 * * *$ & $0.757 * * *$ & $3.3 \%$ & 340 \\
$\mathrm{GVD}^{500}$ & $0.041 * * *$ & $0.936 * * *$ & $3.6 \%$ & 340 \\
$\mathrm{DS}$ & -0.005 & 2.170 & $1.9 \%$ & 341 \\
$\mathrm{TS}$ & 0.010 & 0.593 & $0.5 \%$ & 341 \\
$\mathrm{DP}$ & $0.132 * *$ & $0.034 *$ & $1.8 \%$ & 341 \\
$\mathrm{CAPE}$ & $0.059 * * *$ & $-0.002 * *$ & $2.1 \%$ & 341 \\
$\mathrm{CAY}$ & $0.017 * * *$ & $0.826 * * *$ & $2.7 \%$ & 239 \\
$\mathrm{IK}$ & $0.160 * * *$ & $-3.996 * * *$ & $3.0 \%$ & 259 \\
BM & -0.030 & $0.084 * *$ & $4.0 \%$ & 341 \\
CRSPNPY & $0.188 * * *$ & $0.079 * *$ & $2.4 \%$ & 336
\end{tabular}

\section{Monthy 5-year bond returns}

\begin{tabular}{llcc}
\multicolumn{1}{c}{$\mathrm{a}$} & \multicolumn{1}{c}{$\mathrm{b}$} & \multicolumn{1}{c}{$\mathrm{R}^{2}$} & $\mathrm{~N}$ \\
\hline $0.002 * * *$ & $0.042 * *$ & $0.7 \%$ & 826 \\
$0.002 * * *$ & $0.052 * *$ & $0.7 \%$ & 826 \\
-0.001 & 0.228 & $0.6 \%$ & 826 \\
-0.000 & $0.092 *$ & $0.8 \%$ & 826 \\
0.000 & -0.000 & $0.0 \%$ & 826 \\
0.001 & -0.000 & $0.0 \%$ & 826 \\
0.001 & $0.106 * *$ & $1.2 \%$ & 234 \\
0.005 & -0.111 & $0.1 \%$ & 250 \\
0.002 & -0.001 & $0.0 \%$ & 826 \\
-0.001 & -0.001 & $0.0 \%$ & 826 \\
\hline & & &
\end{tabular}

\begin{tabular}{|c|c|c|c|c|c|c|c|c|}
\hline & & Quarterly & $\overline{\text { SDPG }}$ & & & Quarterly & FIG & \\
\hline & $\mathrm{a}$ & $\mathrm{b}$ & $\mathrm{R}^{2}$ & $\mathrm{~N}$ & $\mathrm{a}$ & $\mathrm{b}$ & $\mathrm{R}^{2}$ & $\mathrm{~N}$ \\
\hline $\mathrm{GVD}^{250}$ & $0.006 * * *$ & $-0.070 * * *$ & $4.1 \%$ & 260 & $\overline{0.003}$ & $-0.249 * * *$ & $6.9 \%$ & 260 \\
\hline $\mathrm{GVD}^{500}$ & $0.006 * * *$ & $-0.081 * * *$ & $3.6 \%$ & 260 & 0.003 & $-0.277 * * *$ & $5.6 \%$ & 260 \\
\hline $\mathrm{DS}$ & $0.012 * * *$ & $-0.487 * * *$ & $4.9 \%$ & 260 & $0.024 * * *$ & $-1.609 * *$ & $7.1 \%$ & 260 \\
\hline $\mathrm{TS}$ & $0.007 * * *$ & 0.057 & $0.6 \%$ & 260 & 0.003 & $0.340 * *$ & $3.0 \%$ & 260 \\
\hline DP & 0.009 & 0.000 & $0.0 \%$ & 260 & -0.010 & -0.005 & $0.8 \%$ & 260 \\
\hline CAPE & $0.007 * * *$ & 0.000 & $0.2 \%$ & 260 & 0.002 & 0.000 & $1.1 \%$ & 260 \\
\hline CAY & $0.008 * * *$ & 0.051 & $0.9 \%$ & 239 & $0.009 * * *$ & 0.109 & $0.5 \%$ & 239 \\
\hline IK & $0.019 * *$ & -0.313 & $1.3 \%$ & 260 & $0.043^{*}$ & -0.985 & $1.7 \%$ & 260 \\
\hline $\mathrm{BM}$ & $0.009 * * *$ & -0.001 & $0.1 \%$ & 260 & $0.013 * *$ & -0.008 & $0.5 \%$ & 260 \\
\hline CRSPNPY & 0.012 & 0.002 & $0.2 \%$ & 256 & -0.005 & -0.006 & $0.2 \%$ & 256 \\
\hline
\end{tabular}




\section{Table 3: Predicting stock returns, bond returns, GDP and investment growth out-of-sample}

This table presents results of out-of-sample predictions of a set of dependent variables using a set of predictor variables. The dependent variables include: (1) Quarterly arithmetic excess returns of the CRSP value-weighted index over the monthly risk-free rate, (2) Monthly excess returns of a 5year Treasury bond portfolio over the risk-free rate (3) Quarterly real GDP Growth (GDPG), (4) Quarterly real Private Fixed Investment Growth (PFIG). The predictor variables include interest rate variables, DS and TS (default and term spreads); valuation ratios, DP, CAPE, BM, CRSPNPY (dividend to price, cyclically adjusted price to earnings, book-to-market of the DJIA, and log net payout of all CRSP stocks); as well as macro variables, CAY and IK (consumptionwealth ratio and investment-to-capital ratio). These are described in greater detail in Table 1.We report out-of-sample $R^{2} s$ from expanding window estimations, with the start date for the evaluation period beginning in 1975:1. Statistical significance is assessed based on MSE-F tests (McCracken (2007)) of equal predictive ability between using the historical mean market excess return and the predictor variable. The symbols ***, **, and * represent statistical significance at the $1 \%, 5 \%$ and $10 \%$ levels, respectively.

\begin{tabular}{llllllllc}
\hline & \multicolumn{2}{c}{ MKTRF } & \multicolumn{2}{c}{5 -year Bond } & \multicolumn{2}{c}{ GDPG } & \multicolumn{2}{c}{ PFIG } \\
Variable & OOS R $^{2}$ & $\mathrm{~N}$ & OOS R $^{2}$ & $\mathrm{~N}$ & OOS R $^{2}$ & $\mathrm{~N}$ & OOS R $^{2}$ & $\mathrm{~N}$ \\
\hline GVD $^{250}$ & $6.4 \% * * *$ & 148 & $0.4 \% * *$ & 432 & $-1.4 \%$ & 148 & $9.0 \% * * *$ & 148 \\
GVD $^{500}$ & $6.7 \% * * *$ & 148 & $0.6 \% * *$ & 432 & $3.1 \% * * *$ & 148 & $8.3 \% * * *$ & 148 \\
DS & $-0.3 \%$ & 148 & $-0.9 \%$ & 432 & $4.3 \% * * *$ & 148 & $11.2 \% * * *$ & 148 \\
TS & $-2.3 \%$ & 148 & $0.2 \% *$ & 432 & $-9.9 \%$ & 148 & $-3.8 \%$ & 148 \\
DP & $-5.3 \%$ & 148 & $-0.5 \%$ & 432 & $-1.6 \%$ & 148 & $-2.9 \%$ & 148 \\
CAPE & $-8.8 \%$ & 148 & $-0.8 \%$ & 432 & $-6.2 \%$ & 148 & $-3.8 \%$ & 148 \\
CAY & $-1.6 \%$ & 148 & $-1.5 \%$ & 144 & $-2.8 \%$ & 148 & $-0.1 \%$ & 148 \\
IK & $-2.6 \%$ & 148 & $-0.3 \%$ & 144 & $0.3 \%$ & 148 & $-3.5 \%$ & 148 \\
BM & $-15.1 \%$ & 148 & $-1.0 \%$ & 432 & $-9.2 \%$ & 148 & $-7.4 \%$ & 148 \\
CRSPNPY & $-10.6 \%$ & 145 & $-0.5 \%$ & 432 & $-0.9 \%$ & 145 & $-3.1 \%$ & 145 \\
\hline
\end{tabular}




\section{Table 4: Predicting the equity premium using GVD}

This table presents results of regressions predicting excess returns of the CRSP value-weighted market index over the 3-month Treasury bill rate with an intercept and GVD. Panel A presents full-sample regressions predicting quarterly, non-overlapping excess market returns with $\mathrm{GVD}^{250}$ and includes specifications with OLS, Newey-West, and Stambaugh bias-corrected standard errors. The Stambaugh correction is done using the method in Amihud and Hurvich (2004). Panel B shows results of these regressions for three approximately equal sub-samples, 1927:1-1955:2, 1955:3-1983:3, 1983:4-2011:4. All regressions in Panel B are with non-overlapping returns and Stambaugh bias-corrected standard errors. Panel C displays results for both $\mathrm{GVD}^{250}$ and $\mathrm{GVD}^{500}$ for three different predictions horizons, monthly, quarterly (for GVD 500 only, GVD ${ }^{250}$ shown in Panel A), and annual (with quarterly overlap) with Newey-West (5 lags) standard errors to correct for the overlap. Panel D displays the results of additional robustness tests. 'NEWEX dum' controls for the creation of the NASDAQ and the AMEX by including a dummy variable NEWEX equal to one in the first year of each of these exchanges, zero otherwise. 'EX-NEWEX' excludes the two years where NEWEX equals one. 'Ex-Internet' ends the sample in 1996, to exclude the internet period, and 'Ex-1970s' excludes the 1970s, in order to exclude the oil shocks. 'FF' controls for annual returns of the market, HML, and SMB over the past year. 'Skip' skips a quarter between measuring GVD and forecasting market returns. The symbols ***, **, and * represent statistical significance at the $1 \%, 5 \%$ and $10 \%$ levels, respectively. T-statistics are in parentheses.

Panel A: Full-sample regressions: OLS, Stambaugh bias corrected, and Newey West (3 lags)

\begin{tabular}{llll}
\hline \multirow{2}{*}{ Intercept } & OLS & OLS-Stam & OLS-NW \\
\cline { 2 - 4 } & $0.038^{* * *}$ & $0.038^{* * *}$ & $0.038^{* * *}$ \\
$\mathrm{GVD}^{250}$ & $(4.67)$ & $(4.86)$ & $(4.15)$ \\
& $0.757 * * *$ & $0.742^{* * *}$ & $0.757 * * *$ \\
$\mathrm{R}^{2}$ & $(3.37)$ & $(3.30)$ & $(3.74)$ \\
$\mathrm{N}$ & $3.3 \%$ & $3.3 \%$ & $3.3 \%$ \\
\hline
\end{tabular}

Panel B: Sub-samples

\begin{tabular}{|c|c|c|c|}
\hline & 1927:1-1s & 1955:3-1s & 1983:4-2011:4 \\
\hline \multirow[t]{2}{*}{ Intercept } & $0.056 * * *$ & $0.033 * * *$ & $0.029 * * *$ \\
\hline & (2.89) & $(3.32)$ & (3.03) \\
\hline \multirow[t]{2}{*}{$\mathrm{GVD}^{250}$} & 1.018 & $0.780 * * *$ & $0.486^{*}$ \\
\hline & (1.43) & $(2.74)$ & (1.92) \\
\hline $\mathrm{R}^{2}$ & $2.5 \%$ & $6.8 \%$ & $3.8 \%$ \\
\hline $\mathrm{N}$ & 114 & 113 & 113 \\
\hline
\end{tabular}


Table 4: Predicting the equity premium using GVD (contd.)

Panel C: Monthly and annual predictions for GVD ${ }^{250}$ and GVD 500

\begin{tabular}{|c|c|c|c|c|c|}
\hline & Monthly & Monthly & Quarterly & Annual & Annual \\
\hline Intercept & $\begin{array}{l}0.010^{* * *} \\
(4.52)\end{array}$ & $\begin{array}{l}0.011^{* * *} \\
(4.27)\end{array}$ & $\begin{array}{l}0.041 * * * \\
(4.92)\end{array}$ & $\begin{array}{l}0.136 * * * \\
(5.31)\end{array}$ & $\begin{array}{l}0.150 * * * \\
(6.00)\end{array}$ \\
\hline $\mathrm{GVD}^{250}$ & $\begin{array}{l}0.171^{* * *} \\
(2.65)\end{array}$ & & & $\begin{array}{l}2.283^{* * *} \\
(3.70)\end{array}$ & \\
\hline $\mathrm{GVD}^{500}$ & & $\begin{array}{l}0.243^{* * *} \\
(3.21)\end{array}$ & $\begin{array}{l}0.921 * * * \\
(3.48)\end{array}$ & & $\begin{array}{l}3.084 * * * \\
(3.85)\end{array}$ \\
\hline $\mathrm{R}^{2}$ & $0.7 \%$ & $1.0 \%$ & $3.6 \%$ & $7.2 \%$ & $9.3 \%$ \\
\hline $\mathrm{N}$ & 1020 & 1020 & 340 & 337 & 337 \\
\hline
\end{tabular}

Panel D: Robustness to new exchanges, Internet years, 1970s, and Fama-French factors

\begin{tabular}{|c|c|c|c|c|c|c|}
\hline & NEWEX dum & Ex-NEWEX & Ex-Internet & Ex-1970s & $\mathrm{FF}$ & Skip \\
\hline Intercept & $\begin{array}{l}0.038 * * * \\
(4.68)\end{array}$ & $\begin{array}{l}0.037 * * * \\
(4.54)\end{array}$ & $\begin{array}{l}0.040^{* * *} \\
(4.22)\end{array}$ & $\begin{array}{l}0.039 * * * \\
(4.50)\end{array}$ & $\begin{array}{l}0.039 * * * \\
(4.02)\end{array}$ & $\begin{array}{l}0.038 * * * \\
(4.21)\end{array}$ \\
\hline $\mathrm{GVD}^{250}$ & $\begin{array}{l}0.787 * * * \\
(3.35)\end{array}$ & $\begin{array}{l}0.750 * * * \\
(3.15)\end{array}$ & $\begin{array}{l}0.778 * * * \\
(2.88)\end{array}$ & $\begin{array}{l}0.748 * * * \\
(2.99)\end{array}$ & $\begin{array}{l}0.820 * * * \\
(3.79)\end{array}$ & $\begin{array}{l}0.546 * * * \\
(3.08)\end{array}$ \\
\hline NEWEX & $\begin{array}{l}0.018 \\
(0.44)\end{array}$ & & & & & \\
\hline MKTRF12 & & & & & $\begin{array}{l}-0.016 \\
(-0.28)\end{array}$ & \\
\hline HML12 & & & & & $\begin{array}{l}-0.016 \\
(-0.32)\end{array}$ & \\
\hline SMB12 & & & & & $\begin{array}{l}0.050 \\
(0.89)\end{array}$ & \\
\hline $\mathrm{R}^{2}$ & $3.3 \%$ & $2.9 \%$ & $2.9 \%$ & $2.9 \%$ & $3.6 \%$ & $2.9 \%$ \\
\hline $\mathrm{N}$ & 340 & 332 & 281 & 304 & 338 & 339 \\
\hline
\end{tabular}




\section{Table 5: Multivariate equity premium prediction}

This table presents results of multivariate regressions that predict the quarterly equity premium (excess returns of the value-weighted market index over the Treasury bill rate) with $\mathrm{GVD}^{250}$.and our set of benchmark predictors. The benchmark predictors are interest rate variables, DS and TS (default and term spreads); valuation ratios, DP, CAPE, BM, CRSPNPY (dividend to price, cyclically adjusted price to earnings, book-to-market of the DJIA, and log net payout of all CRSP stocks); macro variables, CAY and IK (consumption-wealth ratio and investment-tocapital ratio). Details on these variables are in Table 1. KS refers to 'kitchen-sink' regressions that include all available risk premium predictors. KS-1 includes all variables available from 1926 and KS-2 includes all variables from 1952 (since the start of the availability of quarterly CAY). The table also reports the start and end dates for the dependent variable in each regression. The symbols $* * *, * *$, and * represent statistical significance at the $1 \%, 5 \%$ and $10 \%$ levels, respectively. T-statistics are in parentheses.

\begin{tabular}{|c|c|c|c|c|c|}
\hline & Interest Rate & Valuation & Macro & KS-1 & KS-2 \\
\hline Intercept & $\begin{array}{l}0.011 \\
(0.58)\end{array}$ & $\begin{array}{l}-0.099 \\
(-0.64)\end{array}$ & $\begin{array}{l}0.163^{* * * *} \\
(3.22)\end{array}$ & $\begin{array}{l}-0.114 \\
(-0.73)\end{array}$ & $\begin{array}{l}0.138 \\
(0.77)\end{array}$ \\
\hline $\mathrm{GVD}^{250}$ & $\begin{array}{l}0.721^{* * *} \\
(3.89)\end{array}$ & $\begin{array}{l}0.645^{* * *} \\
(3.21)\end{array}$ & $\begin{array}{l}0.617^{* * *} \\
(3.49)\end{array}$ & $\begin{array}{l}0.671^{* * *} \\
(3.42)\end{array}$ & $\begin{array}{l}0.663 * * * \\
(3.64)\end{array}$ \\
\hline TS & $\begin{array}{l}0.396 \\
(0.79)\end{array}$ & & & $\begin{array}{l}0.977 * \\
(1.65)\end{array}$ & $\begin{array}{l}0.860 * \\
(1.85)\end{array}$ \\
\hline DS & $\begin{array}{l}1.673 \\
(0.77)\end{array}$ & & & $\begin{array}{l}-0.111 \\
(-0.06)\end{array}$ & $\begin{array}{l}0.681 \\
(0.34)\end{array}$ \\
\hline NPY & & $\begin{array}{l}0.039 \\
(0.88)\end{array}$ & & $\begin{array}{l}0.025 \\
(0.56)\end{array}$ & $\begin{array}{l}-0.021 \\
(-0.41)\end{array}$ \\
\hline CAPE & & $\begin{array}{l}0.001 \\
(0.28)\end{array}$ & & $\begin{array}{l}0.002 \\
(0.71)\end{array}$ & $\begin{array}{l}0.003 \\
(1.17)\end{array}$ \\
\hline $\mathrm{BM}$ & & $\begin{array}{l}0.126 \\
(1.28)\end{array}$ & & $\begin{array}{l}0.141 \\
(1.56)\end{array}$ & $\begin{array}{l}0.081 \\
(1.18)\end{array}$ \\
\hline DP & & $\begin{array}{l}-0.038 \\
(-0.92)\end{array}$ & & $\begin{array}{l}-0.021 \\
(-0.50)\end{array}$ & $\begin{array}{l}0.039 \\
(0.66)\end{array}$ \\
\hline CAY & & & $\begin{array}{l}0.682 * * \\
(2.26)\end{array}$ & & $\begin{array}{l}0.588 \\
(1.42)\end{array}$ \\
\hline IK & & & $\begin{array}{l}-3.692 * * * \\
(-2.64)\end{array}$ & & $\begin{array}{l}-4.029 * \\
(-1.82)\end{array}$ \\
\hline $\mathrm{R}^{2}$ & $4.9 \%$ & $7.0 \%$ & $10.6 \%$ & $8.2 \%$ & $12.3 \%$ \\
\hline $\mathrm{N}$ & 340 & 336 & 239 & 336 & 236 \\
\hline Start date & 1927:1 & $1927: 2$ & 1952:2 & $1927: 2$ & 1952:2 \\
\hline End date & $2011: 4$ & $2010: 4$ & $2011: 4$ & $2010: 4$ & $2010: 4$ \\
\hline
\end{tabular}




\section{Table 6: Out-of-sample robustness tests for equity premium prediction}

This table presents results of out-of-sample predictions of the market risk premium (excess returns of the value-weighted market index over the treasury bill rate) using $G^{25 D}{ }^{250}$ and $G_{V D}^{500}$. These are from expanding window estimations, with different start dates for the evaluation period. P-values are for MSE-F tests (McCracken (2007)) of equal predictive ability between using the historical mean market excess return and GVD to forecast the market risk premium. Panel A presents results for quarterly (nonoverlapping) predictions. P-values in Panel A are from critical values in McCracken (2007). Panel B presents results for annual predictions (with quarterly overlap). Pvalues in Panel B are for the MSE-F statistic from a block bootstrap procedure with a block length of four.

\begin{tabular}{|c|c|c|c|c|}
\hline \multirow{2}{*}{ Start } & \multicolumn{2}{|c|}{$\mathrm{GVD}^{250}$} & \multicolumn{2}{|c|}{$\mathrm{GVD}^{500}$} \\
\hline & OOS $\mathrm{R}^{2}$ & p-value & OOS $\mathrm{R}^{2}$ & p-value \\
\hline 1947:1 & $3.9 \%$ & $<0.01$ & $4.1 \%$ & $<0.01$ \\
\hline 1957:1 & $5.0 \%$ & $<0.01$ & $4.9 \%$ & $<0.01$ \\
\hline 1967:1 & $6.0 \%$ & $<0.01$ & $6.6 \%$ & $<0.01$ \\
\hline 1977:1 & $5.5 \%$ & $<0.01$ & $5.9 \%$ & $<0.01$ \\
\hline 1987:1 & $2.3 \%$ & 0.05 & $3.7 \%$ & $<0.01$ \\
\hline
\end{tabular}

Panel B: Annual (with quarterly overlap) market excess returns

\begin{tabular}{|c|c|c|c|c|}
\hline \multirow{2}{*}{ Start } & \multicolumn{2}{|c|}{$\mathrm{GVD}^{250}$} & \multicolumn{2}{|c|}{$\mathrm{GVD}^{500}$} \\
\hline & OOS $\mathrm{R}^{2}$ & p-value & OOS $\mathrm{R}^{2}$ & p-value \\
\hline 1947:1 & $5.3 \%$ & $<0.01$ & $8.4 \%$ & $<0.01$ \\
\hline 1957:1 & $6.2 \%$ & $<0.01$ & $9.3 \%$ & $<0.01$ \\
\hline 1967:1 & $9.3 \%$ & $<0.01$ & $15.2 \%$ & $<0.01$ \\
\hline 1977:1 & $6.8 \%$ & $<0.01$ & $9.7 \%$ & $<0.01$ \\
\hline 1987:1 & $2.1 \%$ & 0.08 & $4.2 \%$ & 0.027 \\
\hline
\end{tabular}




\section{Table 7: The components of GVD}

This table presents results for regressions that predict quarterly non-overlapping excess returns of the CRSP value weighted stock index over the three-month risk free rate. The predictor variables include $\mathrm{GVD}^{250}$ and its two components, $\mathrm{GVD}_{\mathrm{OLD}}$ and $\mathrm{GVD}_{\mathrm{NEW}}$. $\mathrm{GVD}_{\mathrm{OLD}}$ is the difference in returns (excluding dividends) between of the top 250 firms and the market over the last year, while $\mathrm{GVD}_{\mathrm{NEW}}$ is the difference in net new equity capital issuance between the top 250 firms and the market over the past year. All standard errors are Newey-West (with 3 lags). The symbols ***, **, and * represent statistical significance at the $1 \%, 5 \%$ and $10 \%$ levels, respectively. T-statistics are in parentheses.

\begin{tabular}{|c|c|c|c|c|c|c|}
\hline & $(1)$ & $(2)$ & (3) & $(4)$ & (5) & $(6)$ \\
\hline Intercept & $\begin{array}{l}0.038 * * * \\
(4.15)\end{array}$ & $\begin{array}{l}0.042 * * * \\
(4.14)\end{array}$ & $\begin{array}{l}0.036 * * * \\
(3.94)\end{array}$ & $\begin{array}{l}0.019 * * * \\
(3.17)\end{array}$ & $\begin{array}{l}0.021 * * * \\
(3.13)\end{array}$ & $\begin{array}{l}0.043 * * * \\
(4.03)\end{array}$ \\
\hline $\mathrm{GVD}^{250}$ & $\begin{array}{l}0.757 * * * \\
(3.74)\end{array}$ & & & & & \\
\hline $\mathrm{GVD}_{\mathrm{NEW}}$ & & $\begin{array}{l}0.916 \text { *** } \\
(3.47)\end{array}$ & $\begin{array}{l}0.666 * * * \\
(2.86)\end{array}$ & & & $\begin{array}{l}0.869 * * * \\
3.25\end{array}$ \\
\hline $\mathrm{GVD}_{\mathrm{OLD}}$ & & $\begin{array}{l}0.645^{* * *} \\
(3.16)\end{array}$ & & $\begin{array}{l}0.361 * \\
(1.87)\end{array}$ & & \\
\hline SMB12 & & & & & $\begin{array}{l}-0.038 \\
(-0.81)\end{array}$ & $\begin{array}{l}-0.101 * * \\
-2.34\end{array}$ \\
\hline $\mathrm{R}^{2}$ & $3.3 \%$ & $3.5 \%$ & $1.7 \%$ & $0.6 \%$ & $0.2 \%$ & $2.7 \%$ \\
\hline $\mathrm{N}$ & 340 & 340 & 340 & 340 & 340 & 340 \\
\hline
\end{tabular}




\section{Table 8: Cyclical variations in GVD}

This table presents results relating GVD to two aggregate macro-economic variables, real GDP growth (GDPG) and real Private Fixed Investment growth (PFIG). Panel A presents regressions predicting quarterly growth rates in these two variables using GVD and a set of controls. The controls include lagged values of the dependent variable (LAG.Y), the term and default spreads (TS and DS), and annual returns on the market over the past year. Panel B examines whether the forecasting power of GVD is stronger when GDP growth is low. LowGDP is a dummy equal 1 if this quarter's GDP growth is below its full-sample time-series median. We predict the next quarter's market excess return, GDP growth and real fixed private investment growth using GVD and an interaction between GVD and LowGDP. All standard errors are Newey-West (with 3 lags). The symbols $* * *, * *$, and $*$ represent statistical significance at the $1 \%, 5 \%$ and $10 \%$ levels, respectively. T-statistics are in parentheses.

Panel A: Predicting the next quarter's real GDP growth and real private fixed investment growth

\begin{tabular}{|c|c|c|c|c|c|c|}
\hline & \multicolumn{3}{|c|}{ GDPG } & \multicolumn{3}{|c|}{ PFIG } \\
\hline & $(1)$ & $(2)$ & (3) & $(1)$ & $(2)$ & (3) \\
\hline Intercept & $\begin{array}{l}0.007 * * * \\
(6.26)\end{array}$ & $\begin{array}{l}0.005^{* * * *} \\
(4.82)\end{array}$ & $\begin{array}{l}0.007 * * * \\
(3.89)\end{array}$ & $\begin{array}{l}0.004 \\
(1.13)\end{array}$ & $\begin{array}{l}0.002 \\
(0.65)\end{array}$ & $\begin{array}{l}0.005 \\
(1.06)\end{array}$ \\
\hline $\mathrm{GVD}^{250}$ & $\begin{array}{l}-0.061^{* *} \\
(-2.35)\end{array}$ & $\begin{array}{l}-0.056^{* *} \\
(-2.34)\end{array}$ & $\begin{array}{l}-0.039 * \\
(-1.92)\end{array}$ & $\begin{array}{l}-0.243^{* * *} \\
(-3.00)\end{array}$ & $\begin{array}{l}-0.208 * * * \\
(-2.97)\end{array}$ & $\begin{array}{l}-0.141^{* *} \\
(-2.48)\end{array}$ \\
\hline Lag Y & & $\begin{array}{l}0.180^{* * * *} \\
(2.64)\end{array}$ & $\begin{array}{l}0.030 \\
(0.43)\end{array}$ & & $\begin{array}{l}0.224 * * * \\
(3.14)\end{array}$ & $\begin{array}{l}0.077 \\
(1.13)\end{array}$ \\
\hline TS & & & $\begin{array}{l}0.068 \\
(1.57)\end{array}$ & & & $\begin{array}{l}0.391 * * * \\
(3.55)\end{array}$ \\
\hline DS & & & $\begin{array}{l}-0.285^{*} \\
(-1.95)\end{array}$ & & & $\begin{array}{l}-1.080 * * \\
(-2.55)\end{array}$ \\
\hline MKTRF12 & & & $\begin{array}{l}0.020^{* * *} \\
(5.60)\end{array}$ & & & $\begin{array}{l}0.058 * * * \\
(5.19)\end{array}$ \\
\hline $\mathrm{R}^{2}$ & $3.0 \%$ & $7.2 \%$ & $21.8 \%$ & $6.4 \%$ & $12.0 \%$ & $32.4 \%$ \\
\hline $\mathrm{N}$ & 260 & 258 & 258 & 260 & 258 & 258 \\
\hline
\end{tabular}

Panel B: Forecasting with GDP growth interaction

\begin{tabular}{lllll}
\hline & \multicolumn{1}{c}{ MKTRF } & \multicolumn{1}{c}{ GDPG } & \multicolumn{1}{c}{ PFIG } & 5-year bond \\
\hline Intercept & $0.027^{* * *}$ & $0.010^{* * *}$ & $0.013^{* * *}$ & 0.002 \\
\multirow{2}{*}{ GVD } & $(3.52)$ & $(9.32)$ & $(4.32)$ & $(1.36)$ \\
& 0.264 & -0.031 & $-0.166^{* *}$ & 0.016 \\
\multirow{2}{*}{ GVD*LowGDP } & $(1.29)$ & $(-1.11)$ & $(-2.18)$ & $(0.39)$ \\
& $\left(2.113^{* * *}\right.$ & $-0.120^{* * *}$ & $-0.302^{* *}$ & 0.095 \\
Low GDP & 0.013 & $(-2.77)$ & $(-2.10)$ & $(1.46)$ \\
& $(1.05)$ & $-0.007^{* * *}$ & $-0.020^{* * *}$ & 0.000 \\
$\mathrm{R}^{2}$ & $6.2 \%$ & $(-4.30)$ & $(-4.26)$ & $(0.19)$ \\
$\mathrm{N}$ & 258 & $10.8 \%$ & $15.6 \%$ & $1.3 \%$ \\
\hline
\end{tabular}




\section{Table 9: Predicting bond returns and returns of 25 portfolios formed from sorts on size and book-to-market}

This table presents results of predicting returns on bonds, and 25 size and book-to-market sorted portfolios with GVD. In Panel A we predict the next month's excess returns over the risk free rate of bond portfolios with maturities ranging from 90 days to 10 years. Control variables include the lagged returns on the bond being predicted, and the term-spread. In Panel B we predict quarterly excess returns on 25 size and book-to-market sorted portfolios over the risk free rate for the 1926-2011 period. We present coefficients on GVD and $\mathrm{R}^{2} \mathrm{~s}$ from these predictive regressions. Panel C presents results of regressions of quarterly non-overlapping returns on the Fama-French factors, HML and SMB on GVD and lagged (quarterly) returns of the respective factor. All standard errors are Newey-West (with 3 lags). The symbols $* * *, * *$, and $*$ represent statistical significance at the $1 \%, 5 \%$ and $10 \%$ levels, respectively. T-statistics are in parentheses.

Panel A: Predicting excess returns of bond portfolios of different maturities

\begin{tabular}{llllll}
\hline & \multicolumn{1}{c}{$90 \mathrm{day}$} & \multicolumn{1}{c}{$1 \mathrm{yr}$} & \multicolumn{1}{c}{$2 \mathrm{yr}$} & \multicolumn{1}{c}{$5 \mathrm{yr}$} & $10 \mathrm{yr}$ \\
\hline Intercept & $0.000^{* * *}$ & $0.001^{* *}$ & 0.001 & 0.001 & -0.000 \\
& $(5.07)$ & $(2.41)$ & $(1.45)$ & $(0.52)$ & $(-0.18)$ \\
GVD $^{250}$ & 0.001 & $0.016^{* * *}$ & $0.027^{* * *}$ & $0.044^{* *}$ & $0.063^{* *}$ \\
& $(1.27)$ & $(2.95)$ & $(2.80)$ & $(2.41)$ & $(2.22)$ \\
Lagged return & $0.248^{* * *}$ & $0.173^{* * *}$ & $0.156^{* * *}$ & $0.102^{* *}$ & 0.049 \\
& $(3.26)$ & $(3.05)$ & $(3.19)$ & $(2.39)$ & $(1.25)$ \\
$\mathrm{TS}$ & $-0.008^{* *}$ & 0.006 & 0.030 & $0.099^{*}$ & $0.178^{* * *}$ \\
& $(-2.54)$ & $(0.34)$ & $(0.99)$ & $(1.92)$ & $(2.70)$ \\
$\mathrm{R}^{2}$ & $8.3 \%$ & $4.6 \%$ & $4.1 \%$ & $2.7 \%$ & $2.2 \%$ \\
$\mathrm{~N}$ & 985 & 818 & 818 & 815 & 814 \\
\hline
\end{tabular}

Panel B: Predicting size and book-to-market portfolios: quarterly, non overlapping returns

\begin{tabular}{|c|c|c|c|c|c|c|c|}
\hline \multicolumn{8}{|c|}{ Coefficients on GVD 250} \\
\hline & Growth & 2 & 3 & 4 & Value & Dif. & t-statistic \\
\hline Small & $1.348^{* * *}$ & $1.103^{* * *}$ & $1.047 * * *$ & $0.926 * *$ & $0.976 * *$ & $-0.37 *$ & $\overline{(-1.95)}$ \\
\hline 2 & $1.319 * * *$ & $1.056 * * *$ & $0.970 * * *$ & $0.868 * *$ & $0.853 * *$ & $-0.46 * *$ & $(-2.41)$ \\
\hline 3 & $1.298 * * *$ & $0.829 * * *$ & $0.732 * * *$ & $0.721 * *$ & $0.791 * *$ & $-0.507 * *$ & $(-2.45)$ \\
\hline 4 & $0.982 * * *$ & $0.845^{* * *}$ & $0.756 * * *$ & $0.737 * *$ & $0.902 * *$ & -0.08 & $(-0.29)$ \\
\hline Large & $0.813^{* * *}$ & $0.693 * * *$ & $0.568 * * *$ & $0.652 * *$ & $0.520 * *$ & $-0.29 *$ & $(-1.77)$ \\
\hline $\begin{array}{l}\text { Dif. } \\
\text { statistic }\end{array}$ & $\begin{array}{l}-0.54 * \\
(-194)\end{array}$ & $\begin{array}{c}-0.41 \\
(-1.62)\end{array}$ & $\begin{array}{l}-0.48 * \\
(-1.90)\end{array}$ & $\begin{array}{c}-0.27 \\
(-1.30)\end{array}$ & $\begin{array}{l}-0.44^{*} \\
(-1.81)\end{array}$ & & \\
\hline
\end{tabular}

\begin{tabular}{cccccc}
\multicolumn{7}{c}{$\mathrm{R}^{2}$} \\
\hline & Growth & 2 & 3 & 4 & Value \\
\hline Small & $2.2 \%$ & $2.0 \%$ & $1.5 \%$ & $1.2 \%$ & $1.3 \%$ \\
2 & $4.5 \%$ & $2.3 \%$ & $1.9 \%$ & $1.5 \%$ & $1.3 \%$ \\
3 & $3.8 \%$ & $2.6 \%$ & $1.6 \%$ & $1.5 \%$ & $1.0 \%$ \\
4 & $4.5 \%$ & $2.8 \%$ & $2.2 \%$ & $1.5 \%$ & $1.3 \%$ \\
Large & $3.9 \%$ & $3.3 \%$ & $1.6 \%$ & $1.1 \%$ & $0.8 \%$ \\
\hline
\end{tabular}


Table 9: Predicting bond returns and returns of 25 portfolios formed from sorts on size and book-to-market (contd.)

Panel C: Predicting SMB and HML

\begin{tabular}{lll}
\hline & SMB & HML \\
\hline Intercept & $0.014^{* * *}$ & 0.005 \\
& $(2.81)$ & $(0.87)$ \\
GVD $^{250}$ & $0.266 *$ & $-0.321^{* *}$ \\
& $(1.88)$ & $(-2.39)$ \\
Lagged return & -0.026 & -0.050 \\
& $(-0.48)$ & $(-0.48)$ \\
$\mathrm{R}^{2}$ & $1.4 \%$ & $1.6 \%$ \\
$\mathrm{~N}$ & 340 & 340 \\
\hline
\end{tabular}




\section{Figure 1: Time series of $\mathrm{GVD}^{250}$}

This figure shows the time-series of GVD 250 , which is the change in the log weight of the top 250 firms in the aggregate market portfolio over the last 12 months. NBER dated recessions are shaded in gray. Local maxima/minima that are not in or near recessions are indicated by text boxes, that include the date corresponding to the maxima/minima, and the proximate financial market-related event. The symbol "*s" indicates that the maxima/minima does not exactly correspond with the date of the event, or that it is difficult to pinpoint an exact date as the event extends for several months. These events are discussed in the text in greater detail.

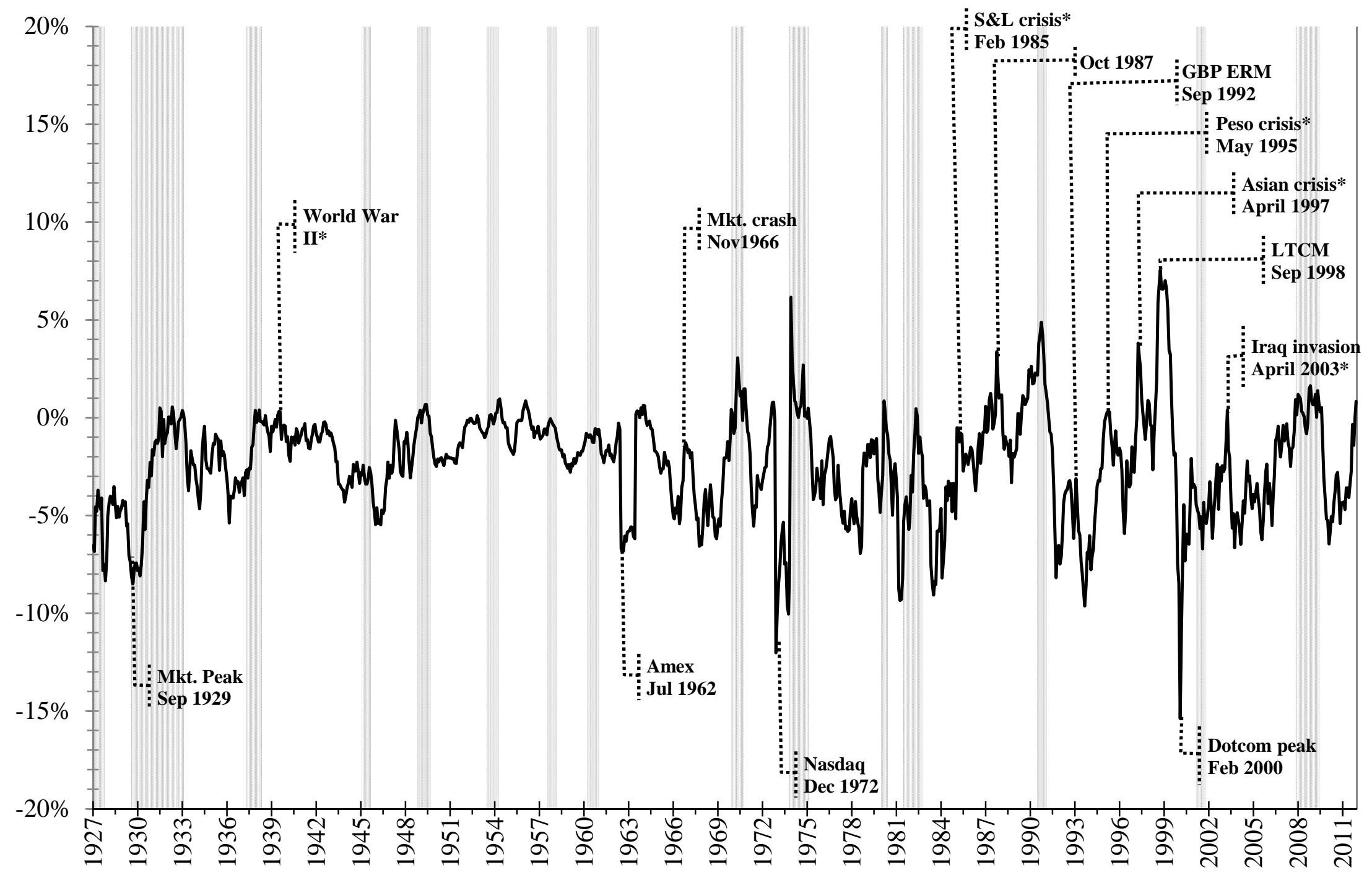




\section{Figure 2: Out-of-sample prediction errors for $\mathbf{G V D}^{250}$}

This figure assesses the performance of out-of-sample forecasts of the market risk premium (excess returns of the value-weighted CRSP index over the Treasury bill rate) made with $\mathrm{GVD}^{250}$ relative to a simple benchmark, the historical average equity risk premium. The figure plots the difference in cumulative sum of squared errors (SSEs) between forecasts made with $\mathrm{GVD}^{250}$ and the historical average equity premium. Both predictions are from expanding window estimation periods, beginning in 1926, with the first estimation window having 20 years of data. Panel A plots differences in SSEs of forecasts of quarterly market excess returns, while Panel B does so for annual market excess returns, with quarterly overlap.

Panel A: Quarterly, non-overlapping prediction errors

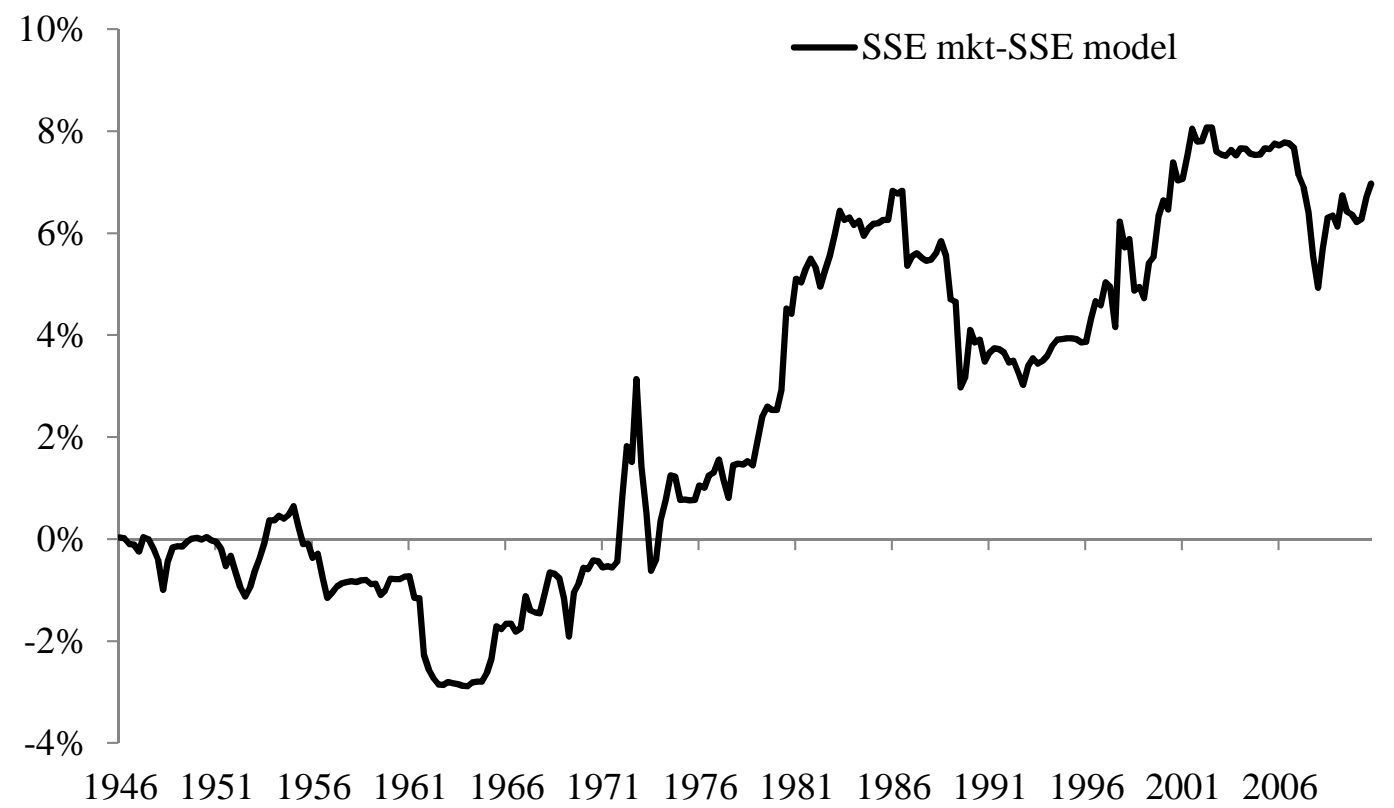

Panel B: Annual, with quarterly overlap prediction errors

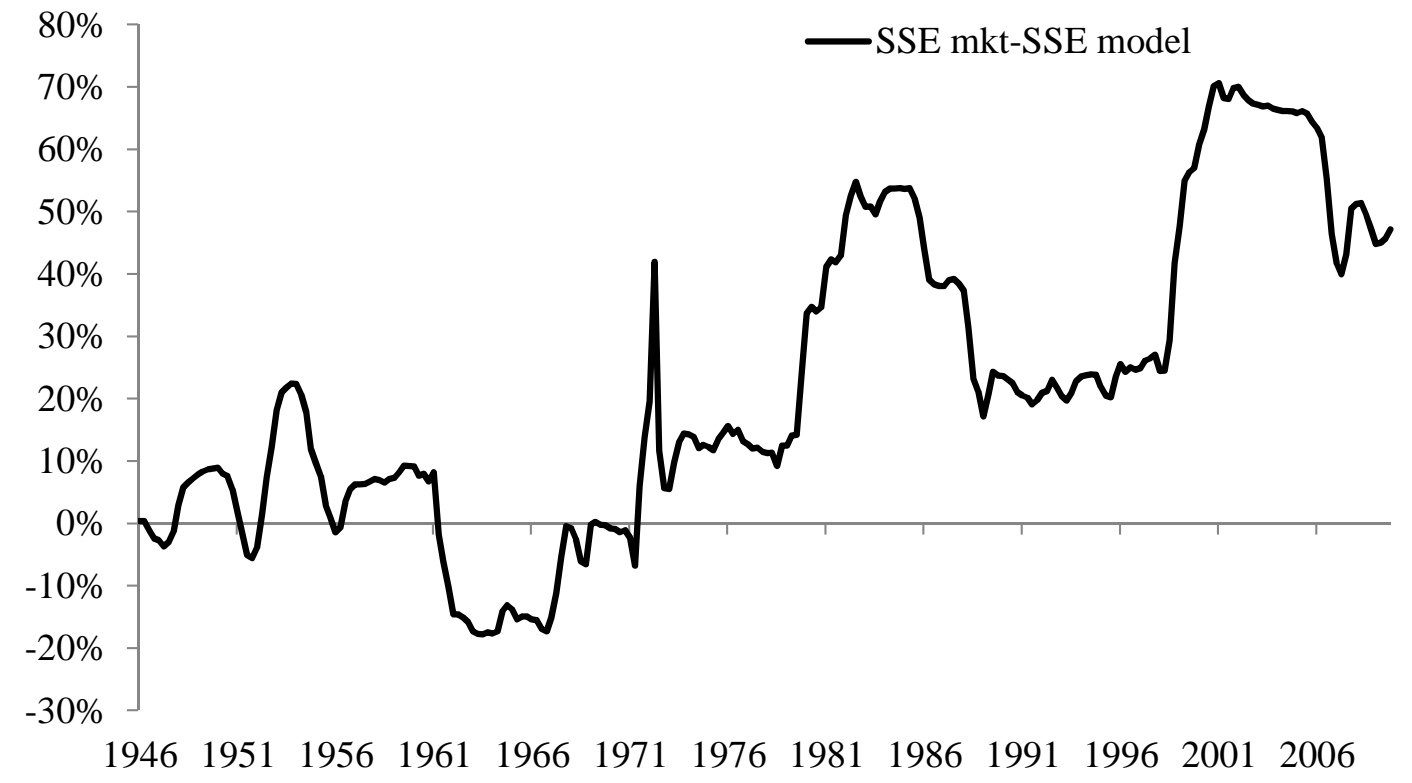

